\title{
Stoichiometrically Governed Curcumin Solid Dispersion and Its Cytotoxic Evaluation on Colorectal Adenocarcinoma Cells
}

This article was published in the following Dove Press journal:

Drug Design, Development and Therapy

\author{
Jamal Moideen Muthu \\ Mohamed' \\ Ali Alqahtani $\left(\mathbb{D}^{2}\right.$ \\ Fazil Ahmad ${ }^{3}$ \\ V Krishnaraju ${ }^{2}$ \\ K Kalpana ${ }^{4}$ \\ 'Department of Pharmaceutical \\ Technology, BIT Campus, Anna \\ University, Tiruchirappalli, Tamil Nadu \\ 620024, India; ${ }^{2}$ Department of \\ Pharmacology, College of Pharmacy, King \\ Khalid University, Guraiger, Abha 62529, \\ Saudi Arabia; ${ }^{3}$ Department of Anesthesia \\ Technology, College of Applied Medical \\ Sciences in Jubail, Imam Abdulrahman Bin \\ Faisal University, Jubail, Saudi Arabia; \\ ${ }^{4}$ Department of Pharmaceutical Analysis, \\ Erode College of Pharmacy, \\ Veppampalayam, Erode, Tamil Nadu \\ 638 II2, India
}

Correspondence: Jamal Moideen Muthu Mohamed

BIT Campus, Anna University,

Tiruchirappalli, Tamil Nadu 620024, India

Tel $+9 \mid-9080018534$

Fax +9l 43I-2407988

Email jmuthumohamed@gmail.com
Background: Colorectal cancer (CRC) is the third most commonly occurring cancer in men and the second most commonly occurring cancer in women. Curcumin $(\mathrm{CMN})$ is obtained from a natural source and has no toxicity, even at high doses $(8,000 \mathrm{mg} / \mathrm{kg}$ body weight in 24 hours $)$ and was determined to have anticancer potency on several kinds of carcinoma. However, its medical applications were limited because of its low solubility and poor bioavailability.

Materials and Methods: To improve the medical applications of CMN, various hydrophilic carriers such as poloxamer 407 (PMX-407), poloxamer 188 (PMX-188), Gelucire 50/ 13 (Gel-50/13), and mannitol (MNL) were used to prepare a binary complex solid dispersion (SD). These binary SDs were characterized for aqueous solubility in various solvents. Physical stability, thermal behaviors, and morphology were determined by Fourier transform infrared spectrophotometric analysis, powder X-ray diffraction analysis, thermogravimetric analysis, differential scanning calorimetric analysis, scanning electron microscopy, dynamic light scattering study, and the novel dyeing test. In vitro drug release was determined by dissolution study. Based on the characterization, the better SD complex was optimized using Box-Behnken design (BBD). The cytotoxicity and apoptosis study of prepared CMN (C-SD) were used to test for colorectal adenocarcinoma cell lines.

Results: These results showed that the solubility of CMN is greatly improved after complexation with PXM-407 in SD. CMN is practically insoluble in water at acidic and neutral $\mathrm{pH}$; however, the SD of CMN with PXM-407 produced significant improvement in solubility $(1.266 \pm 0.0242 \mathrm{mg}$ / $\mathrm{mL})$ and dissolution (91.36 $\pm 0.431 \%$ at 30 minutes); similarly, these data fit with a phase solubility study and in silico molecular modeling. Moreover, the solid-state characterization revealed that the SD complex exhibits the intermolecular hydrogen bond with drug and carrier. Also, the complex does not undergo any chemical modification owing to the amorphous form, and the dye test showed better coloring impact indicating the solubility of CMN. The cell cycle arrest confirmed at G2/M phase from flow cytometry analysis, and Western blot investigation was recognized molecular level cell death and the complex induced more exploit DNA during apoptosis.

Conclusion: This study confirmed that the ideal stoichiometric ratio of CMN with carrier to enhance its solubility was 1:1. This molecular complex of PXM-407 was found to be more effective against colorectal cancer (CRC) than pure CMN.

Keywords: curcumin, phase solubility, MTT assay, colorectal cancer, in silico interaction, dissolution comparison

\section{Introduction}

Over the years, natural compounds have been explored as an alternative to conventional cancer therapies such as surgery, radiotherapy, and chemotherapy. Synthetic 
anticancer drugs may develop toxicity and have various sideeffects such as bone marrow depression, alopecia, extreme fatigue, loss of self-esteem, loss of immunity, and a remarkable decline in WBC count. The insoluble properties of anticancer drugs lead to accumulation at the absorption site and lead to toxicity. ${ }^{1}$ The dosing frequency can be minimized by establishing the proper dosage form to deliver the drug over an extended period.

Curcumin (CMN), is an active constituent of turmeric and has gained much attention as an anticancer agent due to its ability to regulate multiple cell signaling pathways. Numerous studies have proven that the active principle (lipophilic polyphenol) component of CMN produces various anticancer activity, in contrast to its low aqueous solubility and stability as well as its quick metabolism and elimination, causing its therapeutic application to be limited. To overcome these demerits, soluble CMN is prepared as a binary complex with carriers of solid dispersion (SD). ${ }^{2,3}$

Curcumin has been used in traditional Indian medicine for many centuries for its anti-inflammatory and anti-carcinogenic properties. There has been some promising research concerning curcumin as a safe therapeutic agent for many cancers, colorectal cancer being among them. This has been shown through research in cell cultures, animal models, and humans. At this time, it appears that curcumin's anti-carcinogenic properties are most likely due to its effects on multiple molecular targets, such as nuclear factor $\kappa$-light-chain-enhancer of activated $B$ cells $(\mathrm{NF}-\kappa \mathrm{B})$ and activator protein 1 (AP-1). NF- $\kappa \mathrm{B}$ and AP-1 are both major transcription factors that regulate inflammation and thus affect cell proliferation, differentiation, and even apoptosis. ${ }^{4}$ Curcumin has also been shown to affect a variety of other key players involved in carcinogenesis, such as cyclooxygenase-2, matrix metallopeptidases 2 and 9, and tumor necrosis factor $\alpha$ induced vascular cell adhesion molecule, just to name a few. Although many molecular targets are involved, $\mathrm{CMN}$ has been well tolerated in many studies: doses up to $8 \mathrm{~g}$ /day have been confirmed to be safe for humans. In this brief review, we will examine the current studies and literature and touch upon many molecular pathways affected by curcumin, and demonstrate the exciting possibility of curcumin as a chemopreventive agent for colorectal cancer. ${ }^{5}$ A number of preclinical studies have demonstrated that $\mathrm{CMN}$ could be a promising anticancer drug. Garcea et al $^{6,7}$ reported that $\mathrm{CRC}$ patients (sample size: 3) received $3.6 \mathrm{~g} /$ day of $\mathrm{CMN}$ and showed a plasma concentration level below $1 \mathrm{ng} / \mathrm{mL}$. They believe this compound could be a promising tool when testing the potential anticancer effects of $\mathrm{CMN}$ in clinical trials.

The enhancement of the solubility of insoluble drugs is important and one of the most challenging tasks in present-day drug research. The diverse physicochemical methodologies that have been explored to enhance drug solubility include the addition of surfactants, nanosizing, and micronization, conversion to the amorphous state, increasing wettability, developing prodrugs and salts, the liposome approach, and solid dispersion (SD). Micronization of drugs is not suitable for drugs having a high dose number because it does not change the saturation solubility of the drug. Nano technology has been developed for efficient delivery of hydrophobic drugs. Another novel nanosizing and solubilization technology whose application has increased in recent years is particle size reduction via supercritical fluid (SCF) processes. Cryogenic methods have been developed to enhance the dissolution rate of drugs by creating nanostructured amorphous drug particles with a high degree of porosity at very low-temperature conditions. ${ }^{8}$ The use of surfactants to improve the dissolution performance of poorly soluble drug products is probably the basic, primary, and the oldest method. Surfactants reduce surface tension and improve the dissolution of lipophilic drugs in aqueous medium.

The basic mechanism through which SD improves the solubility of insoluble powder is blending a carrier and drug. When a solid molecular compound is subjected to a high energy mill, its structural and microstructural characters change considerably as well as its physical and chemical stability. All these changes may have a significant impact on biopharmaceutical properties, eg, enhanced solubility and bioavailability. ${ }^{9}$ Principle advantages are: the drug is molecularly dispersed in the dissolution medium, enhancing drug solubility in relation with drug wettability can usually be achieved using the drug in its amorphous state, and the linear polymers yield greater porous particles than those containing reticular polymers resulting in a higher dissolution rate. ${ }^{10}$

The rationale of the present research in this investigation is i) the utilization of different carriers in the preparation of complex SD, ii) the investigation of thermodynamic parameters including interaction of an in silico model to determine the suitable complex to enhance the solubility of CMN in maximum level, iii) optimization of variable responses for the preparation of SD complex, 
iv) the complexes exposed by in vitro dissolution and its physicochemical characterization, and v) upgrading best complex in hostile to cancer action by altering its mild cytotoxic profile against the colorectal adenocarcinoma cells (SW480 cells).

\section{Materials and Methods Drug, Carriers, and Reagents}

Curcumin (CMN; purity $>99 \%$ ) was provided by SRL Pvt. Ltd (Maharashtra, India), Mannitol (MNL) and poloxamers (PXM-407 and 188) by S.D. Fine Chem. Pvt. Ltd (India), and Gelucire 50/13 was gifted from Gattefosse Pvt. Ltd (Mumbai, India). Other reagents and chemicals utilized were based on the grade of analytics.

\section{Cell Culture}

The colorectal adenocarcinoma cell lines of SW480 were obtained from the National Center for Cell Science (NCCS), Pune. The cells were cultured in Dulbecco's Modified Eagle's medium (DMEM; Sigma-Aldrich, USA) supplemented with $10 \%$ fetal bovine serum and $20 \mathrm{~mL}$ of $1 \%$ penicillin/streptomycin (Hi-media, Mumbai, India) as an antibiotic at $37^{\circ} \mathrm{C}$ in a humidified environment of $5 \%$ carbon dioxide using a carbon dioxide incubator (Thermo Scientific, USA).

\section{Phase Solubility Study}

The phase solubility (PS) study was carried out as per Higuchi and Connors protocol with slight modification. ${ }^{11}$ Briefly, an excess amount of aqueous solution $(25 \mathrm{~mL})$ of different CMN concentrations (1-15\%) was added to the carriers (PXM-407/PXM-Gel-50/13/MNL) in Eppendorf tubes which were placed in a water bath at a steady temperature of 25 or $37^{\circ} \mathrm{C} \pm 1{ }^{\circ} \mathrm{C}$ for 24 hours to ensure that equilibrium, they were shaken at 30 minute intervals. The mixtures were then filtered through a $0.45 \mu \mathrm{m}$ membrane filter, the filtrate diluted appropriately, and the maximum absorbance (at $425 \mathrm{~nm}$ ) was measured using a Ultraviolet spectrophotometer (Agilent Cary 60 UV-Vis Spectrophotometer, USA). The stability complexation constant $\left(\mathrm{K}_{1: 1}\right)$ was ascertained (Equation 1) by using the slope and intercept of the solubility curve, with the intercept being directly proportional to the intrinsic solubility of CMN. ${ }^{12}$

$$
\mathrm{K}_{1: 1}=\frac{\mathrm{S}}{\mathrm{I}(1-\mathrm{S})}
$$

Here, symbols $\mathrm{S}$ and I denote the slope and intercept, respectively. Additionally, the enthalpy change $(\Delta \mathrm{H})$ on complexation was obtained from the Van't Hoff equation (Equation 2).

$$
\ln \left(\frac{\mathrm{K}_{2}}{\mathrm{~K}_{1}}\right)=\Delta \mathrm{H} \frac{\mathrm{t}_{2}-\mathrm{t}_{1}}{\mathrm{Rt}_{2} \mathrm{t}_{1}}
$$

Here, $K_{2}, K_{1}$ and $t_{2}$ and $t_{1}$ refer to the stability constants and corresponding temperatures in Kelvin at 37 and $25^{\circ} \mathrm{C}$, respectively. The Gibbs free energy change $(\Delta \mathrm{G})$ and change in entropy $(\Delta \mathrm{S})$ upon ideal complexation were computed from Equations 3 and 4, respectively.

$$
\Delta \mathrm{G}=-\mathrm{Rt} \ln \mathrm{K}
$$

Here, $\mathrm{R}$ is the universal gas constant $\left(8.314 \mathrm{~J} \cdot \mathrm{mol}^{-1} \cdot \mathrm{K}^{-1}\right)$

$$
\Delta \mathrm{S}=\frac{\Delta \mathrm{H}-\Delta \mathrm{G}}{\Delta \mathrm{T}}
$$

\section{Preparation of Physical Mixtures and Solid Dispersions (PM and SD)}

CMN (100 mg) was used for PM and SD. Physical mixtures (PM) of varying compositions (1:3-1:7 of CMN-tocarrier, respectively) were prepared using a pestle and mortar as specified by the guidelines of geometrical mixing, and by sieving through sieve No. 120 and mesh size 150-125 $\mu \mathrm{m}$. SD complexes of the same compositions were prepared by the following methods.

\section{Melting Method}

The SD was prepared by adding $100 \mathrm{mg}$ CMN to the molten carrier PXM-407/PXM-Gel-50/13/MNL at $70^{\circ} \mathrm{C}$ with constant stirring at $700 \mathrm{rpm}$ for 15 minutes until the product became homogenous. The resulting product was allowed to solidify at $28^{\circ} \mathrm{C}$, after which it was powdered, sieved, and stored in a desiccator. ${ }^{13}$

\section{Characterization of Curcumin Solid Dispersion Drug Content and Yield}

The pure CMN, PM, and SDs (equiv. to CMN wt.) were diluted with $2 \mathrm{~mL}$ of ethanol and sonicated. Further dilutions made with Milli Q water and UV absorbance was measured. The drug content was determined by standard calibration curve at $425 \mathrm{~nm}$ wavelength and then the content of drug was determined by standard calibration curve $(\mathrm{Y}=\mathrm{mX}+\mathrm{C})$ at this wavelength. ${ }^{14}$ The percent yield was calculated with respect to initial amount by the following formula. 


$$
\% \text { Yield }=\frac{\text { weight of the SD }}{\text { Total weight of the drug and carrier }} \text { X100 }
$$

\section{Aqueous Solubility Study}

An excess quantity of sample (pure CMN, SD, or PM) was added to Milli $\mathrm{Q}$ water in a $100 \mathrm{~mL}$ volumetric flask and heated in a water bath at a steady temperature of $37 \pm 1^{\circ} \mathrm{C}$ for 24 hours, with shaking at 30 minute intervals. ${ }^{12}$ Subsequently, the mixture was filtered through a $0.45 \mu \mathrm{m}$ membrane filter, diluted to a suitable concentration using blank (Milli Q water), and the UV absorbance was estimated.

Fourier Transform Infrared Spectrophotometric (FT-IR) Analysis

FT-IR investigation was carried out to assess possible interaction (difference in structure) between the drug and carriers. The spectrum of the PM/SD was studied in the wavenumber range of 4,000-400 $\mathrm{cm}^{-1}$ of solid powder by the $\mathrm{KBr}$ disc scheme with a scan speed of $1 \mathrm{cms}^{-1} \cdot 12$

\section{Powder X-Ray Diffraction (PXRD) Study}

The crystallinity of test samples was analyzed by PXRD. The instrument specifications were $\mathrm{Cu}$ Energy with a $\mathrm{Kb}$ filter of $30 \mathrm{Kv}$ current at $15 \mathrm{~mA}$. The powder samples were analyzed in a $2 \theta$ range of $5-40^{\circ}$ at a degree of $1 \% \mathrm{~min}$ and the outcome computed PC database.

\section{Thermogravimetric Analysis (TGA)}

The TGA analysis was conducted using TGA 4000 with the specification of $30-700^{\circ} \mathrm{C}$ and $20^{\circ} \mathrm{C} / \mathrm{min}$ under nitrogen environment. The flow rate was maintained at $10 \mathrm{~mL} / \mathrm{min}$ throughout. Then $3 \mathrm{mg}$ of powder sample was used to examine the interaction.

\section{Differential Scanning Calorimetric Analysis (DSC)}

CMN carriers' interaction was carried out by DSC analysis. Strictly powdered samples were used to detect the interaction. The specifications of DSC instrument were, temperature ranges from $20-300^{\circ} \mathrm{C}$ and $10^{\circ} \mathrm{C} / \mathrm{min}$ under nitrogen environment. The flow rate was maintained at $20 \mathrm{~mL} / \mathrm{min}$ throughout and $3 \mathrm{mg}$ of the sample was used to examine the enthalpy changes.

\section{Dissolution Study}

The dissolution study was performed in $900 \mathrm{~mL}$ of doubledistilled water at $37 \pm 1^{\circ} \mathrm{C}$ at $50 \mathrm{rpm}$ using a USP dissolution apparatus II. The samples were placed in the jar and time set as zero. At each 5 minute interval for 30 minutes, $5 \mathrm{~mL}$ sample aliquots were syringed out and filtered through
$11 \mu \mathrm{m}$ Whatman filter paper. The percentage of dissolved CMN was estimated by UV spectrometer (at $425 \mathrm{~nm}$; scan range $=200-800$, dual beam, scan rate $=4,800.000 \mathrm{~nm} / \mathrm{min}$ ). A correction for the collective dilution initiated by addition of the sample to the double distilled water was applied to maintain the sink condition. Also, a mechanism of drug release was performed on CMN-SD complexes according to the method described by Dhanalekshmi et al. ${ }^{15}$

\section{Comparison of Dissolution Profile}

Diaz et alEquation 5) ${ }^{16}$ described that the solid dosage form and their dissolution profiles were compared by two mathematical methods with two different factor $(f 1)$ (Equation 5) and similarity factor $\left(f_{2}\right)$ (Equation 6).

$$
\mathrm{f}_{1}=\frac{\sum_{\mathrm{t}=1}^{\mathrm{n}}\left[\mathrm{R}_{\mathrm{t}}-\mathrm{T}_{\mathrm{t}}\right]}{\sum_{\mathrm{t}=1}^{\mathrm{n}} \mathrm{R}_{\mathrm{t}}} \times 100
$$

Where $R_{t}$ and $T_{t}$ are the reference and test analytes at specific time $t$, the number of samples denoted as $n$. The difference factor $\left(f_{1}\right)$ estimates the proportion variation among each curve point of time and the estimation of the relative error among the two curves. If $f_{1}$ is zero, it demonstrates that the two curves are equal. The $f_{2}$ is explained as the logarithmic form of the total square error (Equation 6). The $f_{2}$ is an estimation of the similarity in the current dissolution among the reference and test profile by considering the average total of squares and fit the result between 0 and $100 .^{14}$

$$
\mathrm{f}_{2}=50 \log \left[\left\{1+\frac{1}{\mathrm{n}} \sum_{\mathrm{t}=1}^{\mathrm{n}}\left(\mathrm{R}_{\mathrm{t}}-\mathrm{T}_{\mathrm{t}}\right)^{2}\right\}^{-0.5} \mathrm{X} 100\right]
$$

$f_{2}$ estimates the value ranges from 50-100 confirm similarity of the two curves.

\section{Novel Dyeing Experiment}

A simple novel (first time performed) dye test can be applied to determine the effective solubility of a sample (usually colored) in aqueous media. ${ }^{17}$ Briefly, CMN (10 $\mathrm{mg}$ ) and its SDs (equiv. wt.) were added to double distilled water $(15 \mathrm{~mL})$. The resulting mixture was sonicated for 5 minutes followed by filtration, and then images of the solutions were taken. The above solution was then diluted to $50 \mathrm{~mL}$ and six white linen cloths $\left(8 \times 4.5 \mathrm{~cm}^{2}\right)$ were soaked in it for 1.5 hours. The cloths were then dried at room temperature and observed for color intensity. 


\section{Molecular Modeling}

The BIOVIA material studio and discovery studio 2017 (DS, USA) platform software was used to assess the molecular interaction studies. The structures were collected from the PubChem and ChemBook database. The polymer was converted into a Pdf file and the ligand was saved as .sd format. Adsorption locator module in Material Studio software was used to analyse the location where the molecule will bind with the polymer. Then the binding interaction will be analyzed using the view interaction protocol in discovery studio.${ }^{18}$ Initially, the grid was generated around the carriers of poloxamer and Gel-50/13 with the coordinates of $X(6.123)$, Y (4.641), and Z (0.229), and X (8.543), Y (0.652), and Z (0.043), respectively. Finally the 10 best conformations were selected to study interactions between the carriers and CMN. The carriers were docked (C-Docker protocol in DS) around the drug, and, finally, the stable complex would save for interaction analysis. The CHARMm based algorithm was used to make the interaction between the complexes.

\section{Optimization Using Box-Behnken Design (BBD)}

The BBD was employed for optimization of the SD complex preparation variables. The Design-Expert ${ }^{\circledR}$ Version 12 software trial was used for arithmetical exploration by ANOVA, enabling construction of model equations and 3D response plots for each outcome. Carrier concentration $\left(\mathrm{X}_{1}\right)$, stirring rate $\left(\mathrm{X}_{2}\right)$, and temperature $\left(\mathrm{X}_{3}\right)$, and the corresponding dependent variables $\left(\mathrm{Y}_{1}\right.$ and $\left.\mathrm{Y}_{2}\right)$, aqueous solubility $\left(\mathrm{Sol}_{\mathrm{aq}}, \mathrm{mg} \cdot \mathrm{mL}^{-1}\right)$ and release in 5 minutes $\left(\operatorname{Rel}_{5 \min }, \%\right)$ were the factors that facilitate the preparation of powder complexes. ${ }^{19}$ The quadratic RSM was fitted to the following Equation 7. In each preparation, $100 \mathrm{mg}$ of CMN was used.

$$
\begin{array}{r}
Y=\beta_{0}+\beta X_{1}+\beta_{2} X_{2}+\beta_{3} X_{3}+\beta_{12} X_{1} X_{2}+\beta_{13} X_{1} X_{3}+ \\
\beta_{23} X_{2} X_{3}+\beta_{11} X_{1}^{2}+\beta_{22} X_{2}^{2}+\beta_{33} X_{3}^{2}
\end{array}
$$

\section{Dynamic Light Scattering (DLS) Analysis}

The hydrodynamic particle size (PS), polydispersible index (PDI), and zeta potential (ZP) of the PM and optimized SD complexes were determined by DLS using a Zetasizer Nano ZS90. ${ }^{12}$

\section{Scanning Electron Microscopy (SEM)}

The surface characteristics of samples were examined using SEM to observe electrons moving in zig-zag patterns. The test samples were diluted with Milli Q water (1:100) and dropped on two-sided carbon adhesive tape pre-affixed on a sample stub, then allowed to dry at $28^{\circ} \mathrm{C}$. A thin layer of sample was gold coated (100 $\AA$ ) by a sputter coater, following which the samples were observed at $5.0 \mathrm{kV}^{20}$

\section{MTT Assay}

The cytotoxicity of complexes against the SW480 cell line was estimated by MTT assay as per previous literature. ${ }^{21}$ Briefly, cells were seeded at a density of $5 \times 10^{3}$ cells $\cdot \mathrm{mL}^{-1}$ $\left(200 \mu \mathrm{L} \cdot w^{-1 l^{-1}}\right)$ in 96-well culture plates with DMSO used as the solvent control. After 24 hours of incubation with different concentrations of complex, MTT reagent (5 $\mathrm{mg} \cdot \mathrm{mL}^{-1}, 20 \mu \mathrm{L} \cdot$ well $^{-1}$ ) was added to the medium and incubated at $37^{\circ} \mathrm{C}$ for 4 hours. The resulting purple formazan precipitate was solubilized by the addition of 100 $\mu \mathrm{L}$ DMSO to each well. The cell passage number was 3 . The absorbance of each well was estimated at $570 \mathrm{~nm}$ by a plate reader (Bio-Rad, iMark, USA). Experiments were performed in triplicate and the mean calculated. The $\mathrm{IC}_{50}$ value was determined as the concentration of complex required to decrease the absorbance to half the percentage of the control.

\section{Apoptosis Study Acridine Orange (AO) and Ethidium Bromide (EB) Staining}

The AO/EB dual stain method was used to investigate the apoptotic morphology, with some modifications. Briefly, the $\mathrm{IC}_{50}$ concentration of compounds was used to treat the cells for 24 hours, which were then washed with chilled PBS. Cells were then resuspended in PBS at a concentration of $5 \times 10^{5}$ cells $\cdot \mathrm{mL}^{-1}$, then mixed with $25 \mu \mathrm{L}$ of $\mathrm{AO} /$ EB solution (3.8 $\mu \mathrm{M}$ of $\mathrm{AO}$ and $2.5 \mu \mathrm{M}$ of EB in PBS) on a clean slide. These samples were quickly analyzed by fluorescence microscopy (Carl Zeiss, Axioscope 2plus, Germany) with a UV filter (450-490 nm). For each sample, 300 cells were counted for the number of live, necrotic, or apoptotic cells by staining the nucleus assembly and membrane integrity, and the percentage was calculated. ${ }^{22}$ Morphological variations were also observed and micrographed (400x magnification).

\section{Hoechst Staining}

The SW480 cells were seeded in separate 6-well plates and treated using the $\mathrm{IC}_{50}$ concentrations. After incubation for 24 hours, cells were collected and stained by aqueous Hoechst 33,258 stain at room temperature for 5 minutes. ${ }^{23}$ 
Morphological variations were also observed and micrographed by fluorescence microscopy with a $377-355 \mathrm{~nm}$ filter (400x magnification).

\section{DNA Fragmentation Assay}

DNA fragmentation was performed using the agarose gel electrophoresis method. The SW480 cells were cultured at $1 \mathrm{X} 10^{6}$ cells $\cdot \mathrm{mL}^{-1}$ in 6 -well culture plates. Nearly $70 \%$ of the cells formed a complex which was incubated for 48 hours. After incubation, cells were collected and the pellets centrifuged and washed twice with ice-cold PBS. The pellets were lysed by treating with $10 \mathrm{mM}$ EDTA, $10 \mathrm{mM}$ Tris$\mathrm{HCl}$ and $0.2 \%$; Triton $\mathrm{X}-100$ at $\mathrm{pH} 7.5$ in cold buffer for 10 minutes. The mixtures were then centrifuged at $4{ }^{\circ} \mathrm{C}$ and $13,000 \mathrm{Xg}$ for 10 minutes and the supernatant containing fragmented DNA, RNA, and undamaged chromatin was treated with IA-P-C $(1: 24: 25) .{ }^{24}$ The pellet was washed with $70 \%$ ethanol, dried at room temperature, and dissolved in $20 \mu \mathrm{L} \mathrm{T10E} 1$ buffer adjusted to $\mathrm{pH}$ 7.4. $2 \%$ Agarose gel electrophoresis was utilized to assay $0.6 \% \mathrm{mg} \cdot \mathrm{mL}^{-1}$ of RNase $\mathrm{A}$ at $37^{\circ} \mathrm{C}$ for 30 minutes. In the end, ethidium bromide was used to stain the gels and the DNA fragment observed by UV transillumination.

\section{Flow Cytometry Analysis}

Caco2 and SW480 cells at $1 \times 10^{5}$ cells $\cdot \mathrm{mL}^{-1}$ were incubated with $\mathrm{IC}_{50}$ concentration as mentioned above for 24 hours to analyze the effect of the drug on the cell cycle distribution. The treated cells were collected and washed with phosphate buffer $(\mathrm{pH} 7.4)$, then treated with $80 \%$ ethanol at $4{ }^{\circ} \mathrm{C}$ overnight, then washed twice with cold PBS. The washed cells were treated with propidium iodide stain $\left(40 \mu \mathrm{g} \cdot \mathrm{mL}^{-1}\right)$ and RNase A $\left(100 \mu \mathrm{g} \cdot \mathrm{mL}^{-1}\right)$ in PBS and shaken at $37^{\circ} \mathrm{C}$ for 30 minutes. ${ }^{25}$ The cells were studied by flow cytometry and the percentage of cells in different phases was analyzed using Win MDI 2.9.

\section{Western Blotting for Molecular Apoptosis}

The molecular level apoptosis of SD on SW480 cell line was estimated by Western blot assay. Briefly, cells were seeded at a density of $5 \times 10^{6}$ cells $\cdot \mathrm{mL}^{-1}\left(100 \mu \mathrm{L} \cdot \mathrm{well}^{-1}\right)$ in 100 -well culture plates and treated using the concentration of $\mathrm{IC}_{50}$ for 24 hours. ${ }^{26}$ After 24 hours of incubation, the medium was washed thrice with $0.01 \mathrm{M}$ cold PBS at $\mathrm{pH}$ 7.2. To lyse the content of nucleus cold PBS was used which contains $100 \mu \mathrm{g} / \mathrm{mL}$ PMSF+150 mM NaCl+100 mM Tris- base at $\mathrm{pH} 8+01 \mathrm{mM} \mathrm{NP}-40+0.01 \% \mathrm{NaNO}_{3}+10 \mu \mathrm{M}$ each of leupeptin aprotinin and pepstatin A. After treating with the above solution, protein extract was collected and centrifuged with the specification of $10,000 \times \mathrm{g}$ for 5 minutes at $4^{\circ} \mathrm{C}$. The concentration of protein was measured using BioRad assay Kit. The PVDF membrane comprising SDSPAGE gel (12.5\%) treated with an equal quantity of proteins $\left(100 \mu \mathrm{g}\right.$. lane $\left.^{-1}\right)$, which was immersed overnight with TBST containing $10 \%$ PXM- -407 at $2-4^{\circ} \mathrm{C}$, and the membrane was incubated with primary antibodies $(2-5 \%)$ for 12 hours. ${ }^{27}$ The film was washed with TBST and re-incubated for 2 hours with alkaline phosphatase-conjugated goat antimouse antibody. After 2 hours, immune response due to protein on SW40 cell were developed and photographed by using ECL PLUS detection reagents. The control blotting was analyzed by nitrocellulose film which was treated and incubated with the $\beta$-actin monoclonal antibody at 1:2,000 dilutions for 1 hour.

\section{Results and Discussion Outcome of PS Study}

The PS study confirmed the proposed effect of various carriers on improving the solubility of CMN. A standard linear curve was obtained in the concentration ranges from $5.98 \times 10^{-5}$ to $5.71 \times 10^{-4} \mathrm{mM}$ and $8.16 \times 10^{-5}$ to $7.81 \times 10^{-4}$ $\mathrm{mM}$ for $\mathrm{CMN}$ at 25 and $37^{\circ} \mathrm{C}$, respectively, as shown in Table 1.

The solubility of CMN was enhanced linearly with increasing carrier concentration. This enhancement was due to modification of interactions such as hydrophobic and Van der Waals forces between CMN and the carriers. The slope of the PS curve (usually less than 1) in all carriers revealed a $1: 1$ stoichiometry complex and $A_{L^{-}}$ type phase solubility profiles were reported by Le et $\mathrm{al}^{28}$, and Bandari et al. ${ }^{29}$ The apparent rate constant $\left(\mathrm{K}_{1: 1}\right)$ was calculated from the intrinsic intercept and slope value of solubility curves obtained by plotting the concentration of soluble CMN (\% w/v) against the concentration of the carrier $(\% \mathrm{w} / \mathrm{v})$, as shown in Figure 1.

The stability constant $(\mathrm{Ka})$ of the complexes ranked in the following order, at 25 and $37^{\circ} \mathrm{C}$, respectively: PXM407 (631.9 and 524.9 $\mathrm{M}^{-1}$ ) > PXM-188 (436.48 and $\left.388.28 \mathrm{M}^{-1}\right)>$ GEL-50/13 $\left(100.14\right.$ and $\left.112.05 \mathrm{M}^{-1}\right)>$ MNL $\left(10.88\right.$ and $\left.11.90 \mathrm{M}^{-1}\right)$. The entropy $(\Delta \mathrm{S})$, Gibbs free energy $(\Delta \mathrm{G})$, and enthalpy $(\Delta \mathrm{H})$ were also determined, from the phase solubility diagram. Out of all the carriers, poloxamers, and Gel-50/13 had a perfect 
Table I Outcome of Phase Solubility (PS) Study/Thermodynamic Parameters of CMN with Various Carriers (Mean \pm SD, $n=3$ )

\begin{tabular}{|c|c|c|c|c|c|c|c|}
\hline Carrier & $\mathrm{T}\left({ }^{\circ} \mathrm{C}\right)$ & Intercept (mM) & Slope (M) & $\mathrm{Ka}\left(\mathbf{M}^{-1}\right)$ & $\Delta \mathbf{G}(\mathbf{k J} / \mathrm{mol})$ & $\Delta \mathrm{H}(\mathrm{kJ} / \mathrm{mol})$ & $\Delta S(\mathbf{S J} / \mathrm{mol} \mathrm{K})$ \\
\hline PXM-407 & $\begin{array}{l}25 \\
37\end{array}$ & $\begin{array}{l}5.71 * 10^{-4} \\
7.81 * 10^{-4}\end{array}$ & $\begin{array}{l}0.26484 \\
0.29239\end{array}$ & $\begin{array}{l}631.97 \pm 20.81 \\
524.91 \pm 20.81\end{array}$ & $\begin{array}{l}-15.98 \pm 0.097 \\
-16.25 \pm 0.123\end{array}$ & $-11.9 \pm 0.518$ & $0.01368 \pm 0.002$ \\
\hline PXM-I88 & $\begin{array}{l}25 \\
37\end{array}$ & $\begin{array}{l}2.08 * 10^{-4} \\
4.70 * 10^{-4}\end{array}$ & $\begin{array}{l}0.08261 \\
0.15497\end{array}$ & $\begin{array}{l}436.48 \pm 17.12 \\
388.28 \pm 16.87\end{array}$ & $\begin{array}{l}-I 5.06 \pm 0.224 \\
-I 5.37 \pm 0.245\end{array}$ & $-7.50 \pm 0.490$ & $0.02538 \pm 0.007$ \\
\hline Gel-50/I3 & $\begin{array}{l}25 \\
37\end{array}$ & $\begin{array}{l}2.03 * 10^{-4} \\
2.11 * 10^{-4}\end{array}$ & $\begin{array}{l}0.01998 \\
0.02317\end{array}$ & $\begin{array}{l}100.14 \pm 6.17 \\
112.05 \pm 7.12\end{array}$ & $\begin{array}{l}-11.41 \pm 0.215 \\
-12.16 \pm 0.256\end{array}$ & $7.20 \pm 0.875$ & $0.06245 \pm 0.006$ \\
\hline MNL & $\begin{array}{l}25 \\
37\end{array}$ & $\begin{array}{l}5.98 * 10^{-5} \\
8.16 * 10^{-5}\end{array}$ & $\begin{array}{l}0.00062 \\
0.00094\end{array}$ & $\begin{array}{l}10.88 \pm 1.44 \\
11.90 \pm 1.59\end{array}$ & $\begin{array}{l}-5.78 \pm .0761 \\
-6.33 \pm 0.0892\end{array}$ & $7.35 \pm 0.868$ & $0.04399 \pm 0.002$ \\
\hline
\end{tabular}

complexation constant within the range of $100-1,000 \mathrm{M}^{-1}$; in contrast, MNL showed weak interaction with CMN, which corresponds to that of $\beta$-cyclodextrin inclusion complex, according to the previous paper studied by Iacovino et al). ${ }^{30}$

The determined values of $\Delta \mathrm{G}$ were negative for all carriers, thus confirming the spontaneity of binding. Additionally, $\Delta \mathrm{G}$ decreased with increasing molecular weight of the carrier. The determined values of $\Delta H$ were found to be negative ( $-\Delta \mathrm{H}$; exothermic) in PXM-407 and PXM-188 complexes and $\Delta \mathrm{H}$ observed to be positive (endothermic) in Gel-50/13 and MNL carrier complexes. On the other hand, $\Delta \mathrm{S}$ respective with Gel-50/13 and MNL and system was observed to be high ( 6 and $4 \mathrm{~J} / \mathrm{mol} \mathrm{K}$ ), proving that the complex is endothermic (Figure 1A). The perfect binding constant of poloxamer is due to a polyoxyethylene-polypropylene block-co-polymer with curcumin (HLB value is 18-23). Bodratti and Alexandridis ${ }^{31}$ reviewed the effect of poloxamer polypropylene oxide (PPO), a principal hydrophobic center wherein linked methyl group employing Vander Waals force with CMN undergoing solubilization. However, solubility increased due to polyoxyethylene oxide (PEO) blocked by hydrogen bonding interaction of either oxygen with water molecules.

The endothermic $(+\Delta \mathrm{H})$ process of binding with high $(+\Delta \mathrm{S})$ value $(6.2 \mathrm{~J} / \mathrm{mol} / \mathrm{deg}$.) of Gel-50/13 enhanced wettability while surrounded with a hydrophilic matrix, by reduction of interfacial tension among drug and water (Figure 1B). Cesareo et $\mathrm{al}^{32}$ studied the solubility system of the CMN increase with an increase in concentrations indicating the solvent properties of Gel-50/13. An exception was noticed for MNL where a high $+\Delta \mathrm{S}$ value (4.4 $\mathrm{J} \cdot \mathrm{mol}^{-1} \cdot \mathrm{K}^{-1}$ ) was obtained due to ionization of ligand molecules, resulting in water molecules being less ordered. The binding process was endothermic $(+\Delta H) ; \Delta H$ favors $\Delta \mathrm{G}$ and $\Delta \mathrm{S}$, and the spontaneity ensured by negative $\Delta \mathrm{G}$ meant that at least complex formation occurred between MNL and CMN.

\section{CMN Content and Yield}

The amount of CMN present in the prepared SD ranges from $95.11-98.93 \%$, and the material loss concerning the
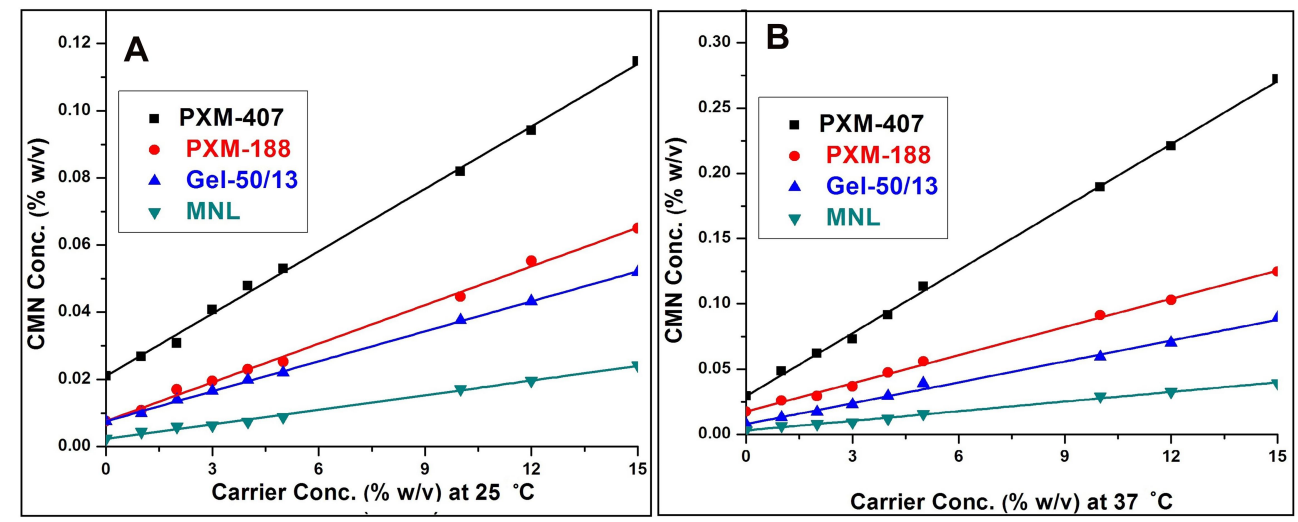

Figure I Phase solubility diagram of CMN in water at $(\mathbf{A})$ at 25 and (B) $37^{\circ} \mathrm{C}$ in the presence of PXM-407, PXM-I88, Gel-50/I3, and $\mathrm{MNL}$. 
CMN content was estimated to be $4.87-12.87 \%$ of the material (Table 2). After SD was prepared, higher loss of material was seen with poloxamers and Gel-50/13, because of sticking property, hydrophobicity of carrier in the semi-solid form.

The high yield was seen in MNL attributed to its higher hydrophilic nature (Table 2), the sum of percent yield ascertained by CMN content, and the proportion of drug and carriers. ${ }^{33}$ The slight distinction between theoretical and practical yield may appear as a result of the accuracy of estimation.

\section{Solubility of CMN}

The solubility of pure $\mathrm{CMN}$ in distilled water was found to be $0.004 \mathrm{mg} \cdot \mathrm{mL}^{-1}$ at $37^{\circ} \mathrm{C}$ after 24 hours (almost insoluble). The solubility of CMN-SD (1:3-1:7) was enhanced by $\sim 270-322$ and $\sim 169-195$-fold with PXM-407 and PXM-188, respectively, as shown in Table 3. Mohanraj and Jasmina ${ }^{34,35}$ studied whether these effects were due to the strong surface active property of the carrier on the surface of the drug molecules. The surface property of surfactant improves the wetting characteristics by decreasing the surface tension of vehicle used, so that drug molecules can penetrate the water environment. Moreover, the viscosity of PXM-188 (1,000 cps) is lower than PXM-407 (3000 cps), which could moderately alter the solubility of CMN from the aqueous environment. Whereas the Gel-50/ 13 binary system showed passionate enhancement of solubility around 121-144 could be due to maximum hydrogen bonding of water molecules to electron-rich Gel-50/13 chain containing oxygen atoms. In contrast, MNL binary
SD showed odder improvement of solubility 16-23 fold due to less interaction with drug molecules.

Overall, the aqueous solubility of CMN in the SDs was enhanced to a greater degree - depending on the carrier concentration - than in the PMs. The aqueous solubility of the PMs was of less importance than the solubility of the SDs due to the partial or improper complexation of the carriers with CMN (Table 3).

\section{Physicochemical Interaction FT-IR}

FT-IR spectra of pure CMN, the carriers, and the PM and SD complexes are shown in Figure 2A. The CMN spectrum contained two peaks corresponding to $-\mathrm{OH}$ (alcohol) stretch vibrations at $3,324.68$ and $3,015.16 \mathrm{~cm}^{-1}$, indicating the presence of two hydroxyl groups. The peaks at $1,742.37$ and $1,629.55 \mathrm{~cm}^{-1}$ indicated the presence of $\mathrm{C}=\mathrm{O}$ (carbonyl) groups in the structure, and were well correlated with the literature. $^{36}$ The $\mathrm{C}-\mathrm{H}$ (alkane) stretch vibrations at 2,922.59 and $2,849.31 \mathrm{~cm}^{-1}$ and $\mathrm{C}=\mathrm{C}$ (aromatic) stretch vibrations at 1,597.73 and $1,507.1 \mathrm{~cm}^{-1}$ were also evident.

The characteristic bands of PXM-407 and PXM-188 (Figure 2A) observed as $\mathrm{O}-\mathrm{H}$ (alcohol) stretching $\left(3,479.92\right.$ and $\left.3,269.72 \mathrm{~cm}^{-1}\right)$, aliphatic $\mathrm{C}-\mathrm{H}$ stretching $\left(2,974.66\right.$ and $\left.2,915.84 \mathrm{~cm}^{-1}\right), \mathrm{C}-\mathrm{O}$ stretching $(1,636.3$ and $\left.1,730.8 \mathrm{~cm}^{-1}\right)$, and alkene $\mathrm{SP}^{2} \mathrm{C}-\mathrm{H}$ bending vibrations (957 and $955.55 \mathrm{~cm}^{-1}$ ). In Gel-50/13 (Figure 2A), peaks at $3,269.72,2,915.84,1,730.8,1,465.63$, and $719.31 \mathrm{~cm}^{-1}$, corresponding to O-H- stretching (alcohol), C-H stretching $\left(\mathrm{SP}^{3}\right), \mathrm{C}-\mathrm{O}$ stretching, C-C stretching, and $\mathrm{C}-\mathrm{H}$ bending vibrations of reduced intensity observed in both $\mathrm{SD}$ and PMs.

Table 2 Percentage of Drug Content of and Total Yield of CMN SD

\begin{tabular}{|c|c|c|c|c|c|}
\hline \multicolumn{6}{|c|}{ Drug Content (\%) } \\
\hline D:C Ratio* & $1: 3$ & $\mathrm{I}: 4$ & I:5 & $1: 6$ & $1: 7$ \\
\hline PXM-407 & $98.74 \pm 2.182$ & $98.31 \pm 1.166$ & $98.91 \pm 1.219$ & $96.03 \pm 1.765$ & $95.11 \pm .854$ \\
\hline PXM- 188 & $98.82 \pm 2.182$ & $98.83 \pm 2.762$ & $98.51 \pm 1.115$ & $97.27 \pm|.57|$ & $96.28 \pm 2.012$ \\
\hline GEL-50/I3 & $97.80 \pm 2.182$ & $96.35 \pm 2.481$ & $95.5 \pm 1.811$ & $97.52 \pm 3.645$ & $94.03 \pm 2.053$ \\
\hline MNL & $98.31 \pm 1.334$ & $99.60 \pm 1.614$ & $98.75 \pm 1.174$ & $98.12 \pm 1.358$ & $98.93 \pm 1.334$ \\
\hline \multicolumn{6}{|c|}{ Total Yield (\%) } \\
\hline PXM-407 & $88.19 \pm 3.15$ & $90.32 \pm 3.453$ & $92.03 \pm 3.589$ & $91.04 \pm 4.543$ & $93.82 \pm 4.871$ \\
\hline PXM-I88 & $87.81 \pm 3.435$ & $87.12 \pm 3.658$ & $90.52 \pm 3.157$ & $88.52 \pm 3.678$ & $89.21 \pm 4.443$ \\
\hline GEL-50/13 & $89.10 \pm 4.211$ & $89.39 \pm 3.124$ & $91.53 \pm 3.985$ & $93.53 \pm 3.982$ & $92.04 \pm 4.671$ \\
\hline MNL & $87.22 \pm 3.414$ & $89.45 \pm 3.223$ & $92.76 \pm 3.35$ & $90.76 \pm 4.457$ & $90.22 \pm 4.974$ \\
\hline
\end{tabular}

Note: *Drug:carrier ratio; (mean $\pm S D, n=3$ ). 
Table 3 Solubility of CMN-PM/SD Complexes

\begin{tabular}{|c|c|c|c|c|c|}
\hline \multicolumn{6}{|c|}{ Aqueous Solubility (mg/mL) } \\
\hline \multicolumn{6}{|c|}{ Pure $\mathrm{CMN}$ at $37^{\circ} \mathrm{C} \quad 0.004 \pm 0.0003$} \\
\hline D:C Ratio* & $\mathrm{I}: 3$ & $1: 4$ & $1: 5$ & $1: 6$ & $1: 7$ \\
\hline \multicolumn{6}{|c|}{ CMN-PM complex } \\
\hline PXM-407 & $0.7122 \pm 0.014$ & $0.7420 \pm 0.032$ & $0.8120 \pm 0.0132$ & $0.8640 \pm 0.0243$ & $0.8760 \pm 0.0543$ \\
\hline PXM-I88 & $0.42 I I \pm 0.037$ & $0.4721 \pm 0.042$ & $0.4823 \pm 0.045$ & $0.5178 \pm 0.034$ & $0.552 I \pm 0.07 I$ \\
\hline GEL-50/I3 & $0.2145 \pm 0.077$ & $0.2267 \pm 0.087$ & $0.2674 \pm 0.065$ & $0.2855 \pm 0.066$ & $0.2910 \pm 0.072$ \\
\hline MNL & $0.02 I I \pm 0.034$ & $0.0225 \pm 0.041$ & $0.0269 \pm 0.04 I$ & $0.029 I \pm 0.063$ & $0.032 I \pm 0.044$ \\
\hline \multicolumn{6}{|c|}{ CMN-SD complex } \\
\hline PXM-407 & $1.0812 \pm 0.022$ & $1.1100 \pm 0.0162$ & $1.2580 \pm 0.0242$ & $1.2500 \pm 0.0225$ & $1.2900 \pm 0.0264$ \\
\hline PXM-I88 & $0.679 I \pm 0.028$ & $0.7017 \pm 0.016$ & $0.7423 \pm 0.024$ & $0.760 I \pm 0.022$ & $0.7798 \pm 0.026$ \\
\hline GEL-50/I3 & $0.4872 \pm 0.028$ & $0.4919 \pm 0.016$ & $0.5288 \pm 0.024$ & $0.5525 \pm 0.025$ & $0.579 I \pm 0.024$ \\
\hline MNL & $0.067 I \pm 0.028$ & $0.0698 \pm 0.025$ & $0.0795 \pm 0.022$ & $0.0812 \pm 0.032$ & $0.0912 \pm 0.034$ \\
\hline
\end{tabular}

Note: *Drug:carrier ratio; (mean $\pm S D, n=3$ ).

The characteristic peaks of MNL observed at 3,398.92, 2,969.84, 2,701.78, 2,513.76, 1,744.3, and $962.30 \mathrm{~cm}^{-1}$ corresponded to $\mathrm{O}-\mathrm{H}, \mathrm{C}-\mathrm{H}, \mathrm{O}-\mathrm{H}$ (carboxylic acid), S-H thiol, $\mathrm{C}-\mathrm{O}$ stretching, and $\mathrm{C}-\mathrm{H}$ bending vibrations, respectively. In the PM and SD of CMN-MNL, there was a marked decrease in the intensity of $\mathrm{OH}$ stretching vibrations compared to in the CMN spectrum (Figure 2A). The $\mathrm{C}-\mathrm{H}$ stretching vibration due to $\mathrm{MNL}$ was sustained both in the SD and PM. The significantly decreased intensity of the $\mathrm{C}=\mathrm{O}$ peak of $\mathrm{CMN}$ in the complex indicated a hydrogen bonding interaction. Our result is in accordance with a similar study reported by Zajc et al. ${ }^{37}$

\section{PXRD}

The PXRD patterns of CMN, the carriers, PMs, and SDs are shown in Figure 2B. CMN displayed sharp peaks (indicating a crystalline arrangement) at $2 \theta=8.98^{\circ}$ and $17.38^{\circ}$, and many tiny peaks at $23.48^{\circ}, 24.72^{\circ}, 25.68^{\circ}, 26.22^{\circ}$ and $27.5^{\circ}$ were complied with the reported data from Jang et al. ${ }^{38}$ The carrier typical peaks such as PXM-407 ( $2 \theta$ of $19.26^{\circ}$ and $23^{\circ}$ ), PXM$188\left(2 \theta\right.$ of $19.24^{\circ}$ and $23.32^{\circ}$ ) indicate the crystalline domain of amorphous polymeric material. In contrast, Gel-50/13 showed amorphous characteristics due to a lack of complete stereo uniformity and the presence of the large lateral group in the carrier were already reported by Avinash et al. ${ }^{39}$ In Figure 2B, both PM and SD of CMN-Gel-50/13 exhibited an amorphous nature with reduced intensity at $2 \theta$ of $8.98^{\circ}$ and $17.38^{\circ}$ compared with crystalline CMN. The amorphous nature of carrier had been established at SD entirely in their respective diffractogram. Many diffraction points with high intensity were observed for MNL, with strong and intense peaks at $2 \theta=18.96,21$, and $23.54^{\circ}$. The same MNL X-ray
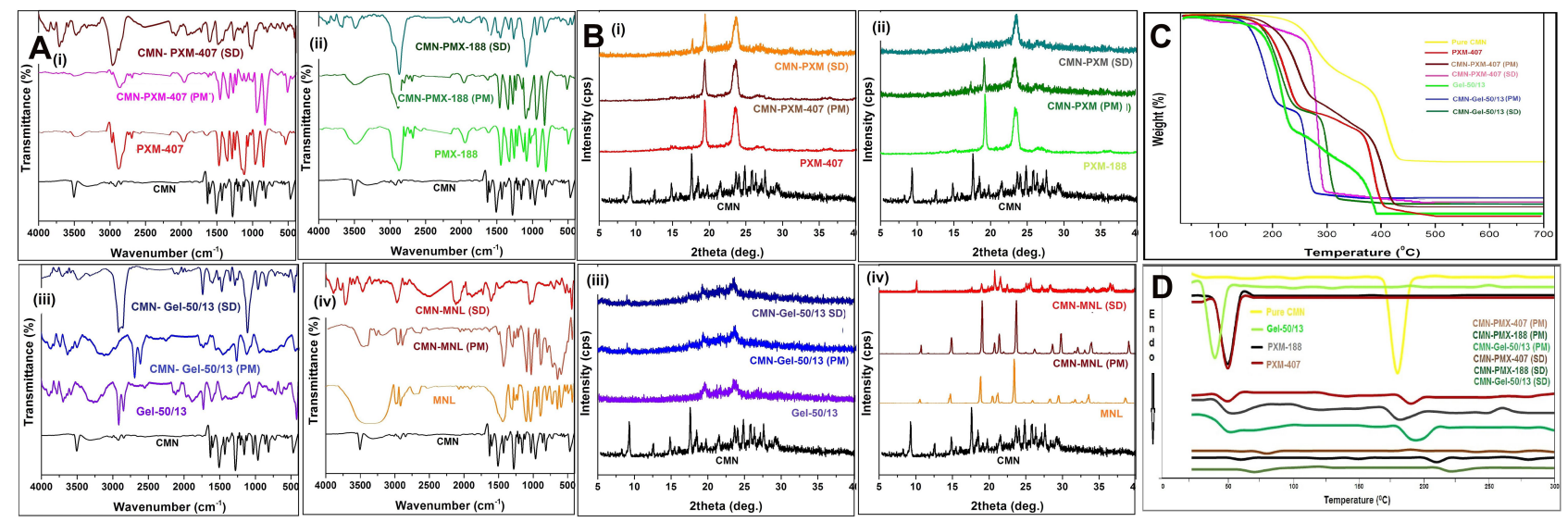

Figure 2 FT-IR spectrum (A), PXR pattern (B), TGA (C), and (D) DSC thermogram of PM and SD. 
diffraction pattern was observed in the PM. In contrast, the $\mathrm{CMN}$ peak at $2 \theta=9.28^{\circ}$ was decreased in intensity in the SD; this was because there were no changes in crystallinity and the peaks of MNL remained unchanged, Fini et al ${ }^{40}$ examined who had obtained the data from PXRD, which indicated that there was little interaction between the drug and this carrier.

\section{TGA}

Figure 2C shows the TGA analysis of thermal degradation of pure CMN, carriers, and SDs. The curve of CMN weight loss starts from $101^{\circ} \mathrm{C}$ and the whole mass loss was detected at $530^{\circ} \mathrm{C}$, obtained here are in good agreement with data from the literature. ${ }^{41}$ The PM of CMNPXM-407 and CMN-Gel-50/13 exhibits total weight loss found to be at 420 and $396^{\circ} \mathrm{C}$, and the SD complexes decomposes between 305 and $320^{\circ} \mathrm{C}$, respectively. Thermal treatment of the studied carriers showing the differences in thermal decomposition of CMN, PM, and SDs was insignificant, which corresponds to that of CMN, according to the previous papers. ${ }^{42}$ It can be confirmed that there were no possible chemical interactions of SD complex, and these differences between PM and SD during this stage (mass loss) might be a host-guest interaction that could restrict the molecule movement of CMN.

\section{DSC}

The endotherms of $\mathrm{CMN}\left(179.9^{\circ} \mathrm{C}\right), \mathrm{PXM}-407\left(52.8^{\circ} \mathrm{C}\right)$, PXM-188 $\left(53.1^{\circ} \mathrm{C}\right)$, and Gel-50/13 $\left(49.7^{\circ} \mathrm{C}\right)$ and their typical curves haves been shown in Figure 2D. The typical CMN properties of melting, boiling, and sublimation point slightly altered at PM due to the carrier molecules interaction occurred with the drug molecules. A complex system of PXM-407, PXM-188, and Gel-50/13 complete absence of the peak point corresponding to $\mathrm{CMN}$ observed, Popat et $\mathrm{al}^{43}$ studied if these effects could be due to release of water molecules or convert entirely amorphous form or dissolution of crystalline into the molten carrier. The small broad peak near $235^{\circ} \mathrm{C}$ observed in SD of CMN-Gel-50/13, with reduced intensity, may correspond to the melting of $\mathrm{CMN}$ (m.p. $179.8^{\circ} \mathrm{C}$ ) shifted considerably to a higher temperature, indicating a reduction in crystallinity of the drug. ${ }^{35}$

\section{SD and PM Drug Release State}

The average dissolution curves of CMN and its PM/SD are shown in Figure 3A. It is notable that the dissolution rate of pure $\mathrm{CMN}$ was as low as $1.62 \%$ after 30 minutes operation. This was due to its high hydrophobicity. The dissolution rate of the $\mathrm{CMN}$ complexes and the carriers exhibited high burst release as $20-80 \%$ in the initial 5-6 minutes, as shown in Table 4; this showed that the entire molecular complex developed or was converted to an amorphous/crystal lattice. Sadeghi et $\mathrm{al}^{44}$ examined the release of $\mathrm{CMN}$ using polyvinylpyrrolidone as a carrier, which was reported similarly to our results.

After 5 minutes, low quantities of CMN were released at a steady rate for all PMs and SDs, as shown in Figure 3A. In CMN-PXM-407 SD (1:5 ratio), 91.34\% of the CMN was released after 30 minutes operation of dissolution apparatus. In PXM-188 SD (1:6 ratio), 74.39\% release was found after 5 minutes, while $61.35 \%$ release was found after 30 minutes, as shown in Table 5. The two various grades of poloxamers dissolution difference were due to molecular weight (PXM188 of average MW 8,500 compared with the average MW of 12,600 for PXM-407). The CMN-Gel-50/13 SD (1:6 ratio) showed a moderate rate of release about $56.15 \%$ after 30 minutes, as shown in Figure 3A.

Dissolution of these carriers could be due to the metastable supersaturation of CMN in the concentrated wet carrier while in dissolution; this finding is in good accordance with the results obtained from Curcumin-Eudragit ${ }^{\circledR}$ EPO solid dispersion. ${ }^{45}$ Apart from non-ionic attributes, viscosity suggested a perfect part in the dissolution of the drug by increasing the contact of drug with dissolution medium during the drug distributed in the liquid carrier (existence of the smooth matrix system of the drug), and the rapid solidification of the carrier. ${ }^{35}$ The in vitro release demonstrated that the end of burst release, a steady state release profile was seen with all SDs, as can be seen in Table 4.

Rapid dissolution of CMN, slightly less than SD, may be clarified as an in situ complex improvement arising from decreased interfacial tension. Data is presented in Figure 3A. The CMN-SD prepared with MNL was not satisfactory in comparison to the other carriers; this was likely due to the polar effect of the carbohydrates and the formation of hydrogen bonds improving solubilization. This result showed that the limited dissolution rate of MNL could be due to its partial conversion from the crystalline to the amorphous form in the presence of pure $\mathrm{CMN}$. As results of these findings, the low dissolution rate of MNL may be due to inadequate complexation or amorphization of the CMN particles, compared to pure CMN.

\section{Kinetics of Drug Release from CMN-SDs}

In order to determine the best model of drug release pattern, the calculated value of the data from the dissolution profile 

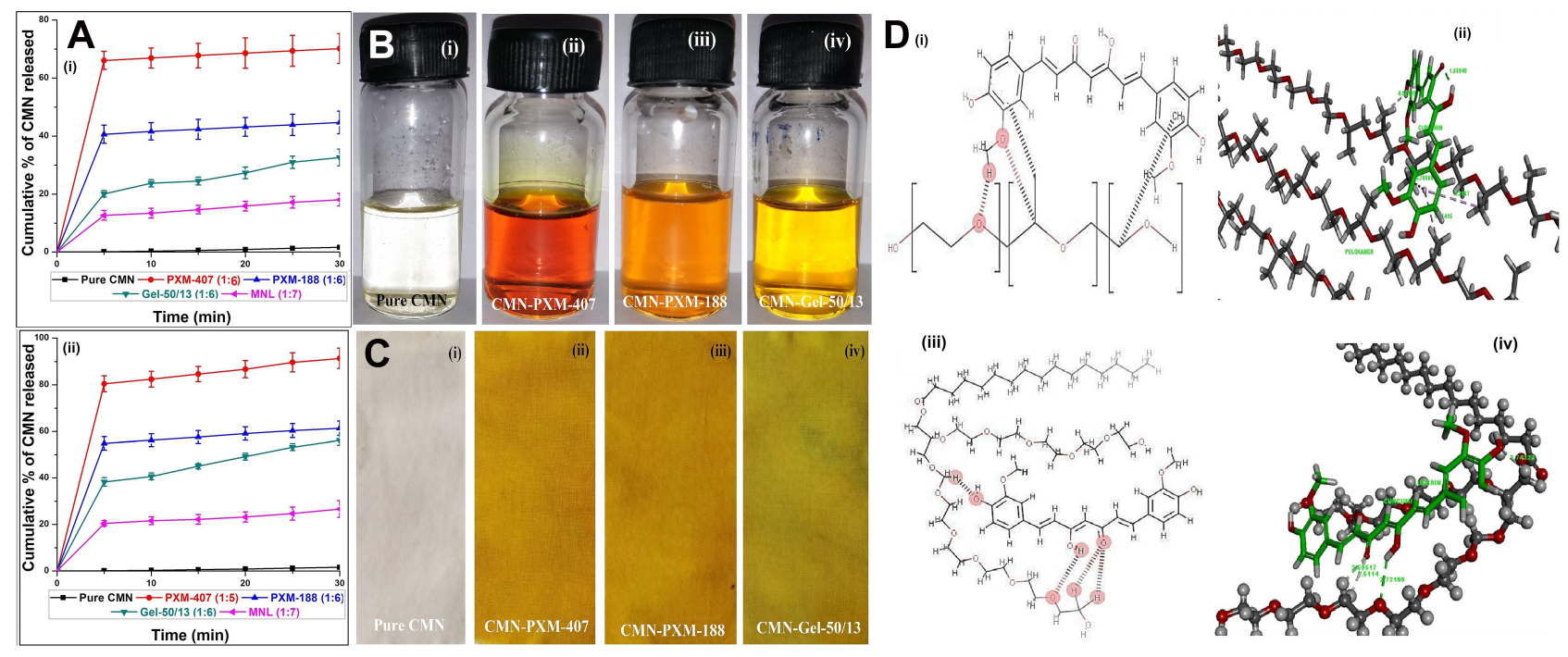

Figure 3 Dissolution curves (A) of CMN (i) CMN-PM and (ii) CMN-SD (mean $\pm S D, n=3$ ), (B) Photograph of the dye test (B) Solution of SD and (C) Cotton clothes dyed in the solution (i) Pure CMN, (ii) CMN- PXM-407, (iii) CMN- CMN-PXM-I88, and (iv) CMN- Gel-50/I3, and (D) Molecular modeling for the I:I complex CMN:PXM and Gel (i) 2D illustration of enol form of CMN on monomer showing hydrophobic bonding of phenolic OH group, (ii) 3D representation of Dock-pose of enol form of CMN, (iii) 2D illustration of a diketo form of CMN showing hydrogen bonding of phenolic OH group, and (iv) 3D representation of Dock-pose of CMN (Green tubes represent the monomer unit of CMN, and Grey tubes represent PXM and Gel, respectively; dotted line indicates most important interactions, and the distances are mentioned in $\AA$ units).

has been substituted with zero order $\left(\mathrm{r}^{2}=0.476-0.712\right)$, first order $\left(\mathrm{r}^{2}=0.536-0.812\right)$, Higuchi $\left(\mathrm{r}^{2}=0.916-0.991\right)$, Hixon Crowell Release $\left(\mathrm{r}^{2}=0.963-0.998\right)$, and Korsmeyer-Peppas $\left(r^{2}=0.866-0.956\right)$, and the release exponent $(n)$ in the range of $0.063-0.221$. Data has been presented in Table 5 . The in vitro release kinetics was the best-fit release mechanism shown by the higher correlation from Hixon Crowell (cubic root of the percent drug remaining vs time). It is known that the rate of release is controlled by the drug particles and not by diffusion. This model has been utilized to show that the release profile may reduce the surface of the drug particles during the dissolution. The release exponent "n" did not obey this model so that it could be a polydispersible product (binary system). This finding is in good accordance with the results obtained for the Hixon Crowell model. ${ }^{46}$ These results were a good argument with the particle size of prepared SD obtained from DLS study.

\section{Assessment of Dissolution Profile}

The precise correlation of dissolution profiles using two analysis factors $f_{1}$ and $f_{2}$ are represented in Table 6.

The cumulative percentage release was used to ascertain the two factors by the SD complex with PXM-188 dissolution data as a reference, due to better stability constant

Table 4 Cumulative Percentage CMN Released from PM and SD

\begin{tabular}{|c|c|c|c|c|c|c|c|}
\hline \multicolumn{8}{|l|}{ CMN-PM } \\
\hline Complex & $\mathbf{T}$ & 5 & 10 & 15 & 20 & 25 & 30 \\
\hline Pure CMN & 0 & $0.1 I \pm 0.02$ & $0.32 \pm 0.04$ & $0.58 \pm 0.04$ & $0.90 \pm 0.06$ & $1.35 \pm 0.06$ & $1.62 \pm 0.07$ \\
\hline PXM-407 (I:6) & 0 & $66.07 \pm 3.12$ & $66.92 \pm 3.45$ & $67.77 \pm 4.23$ & $68.59 \pm 5.25$ & $69.40 \pm 5.36$ & $70.18 \pm 5.13$ \\
\hline PXM-I88 (I:6) & 0 & 40.63 .13 & $41.63 \pm 3.00$ & $42.33 \pm 3.46$ & $43.16 \pm 3.24$ & $43.89 \pm 3.37$ & $44.72 \pm 3.98$ \\
\hline GEL-50/I3 (I:6) & 0 & $20.07 \pm 1.09$ & $23.74 \pm 1.32$ & $24.48 \pm 1.33$ & $27.30 \pm 2.01$ & $30.97 \pm 2.15$ & $32.61 \pm 2.88$ \\
\hline MNL (I:7) & 0 & $12.67 \pm 1.68$ & $13.39 \pm 1.66$ & $|4.62 \pm| .7 \mid$ & $15.85 \pm 1.83$ & $17.14 \pm 2.03$ & $18.06 \pm 2.28$ \\
\hline \multicolumn{8}{|l|}{ CMN-SD } \\
\hline PXM-407 (I:5) & 0 & $80.39 \pm 3.47$ & $82.38 \pm 3.44$ & $84.60 \pm 3.25$ & $88.68 \pm 3.67$ & $89.63 \pm 4.12$ & $91.36 \pm 4.34$ \\
\hline PXM-I88 (I:6) & 0 & $54.83 \pm 2.71$ & $56.23 \pm 2.78$ & $57.55 \pm 2.82$ & $59.05 \pm 2.90$ & $60.31 \pm 2.97$ & $61.35 \pm 3.34$ \\
\hline Gel-50/I3 (I:6) & 0 & $38.24 \pm 2.88$ & $40.63 \pm 2.75$ & $45.02 \pm 2.78$ & $49 .|4 \pm 2.8|$ & $53.22 \pm 2.99$ & $56.15 \pm 3.12$ \\
\hline MNL (I:7) & 0 & $20.48 \pm 1.32$ & $21.58 \pm 1.32$ & $22.20 \pm 1.32$ & $23.20 \pm 1.32$ & $24.72 \pm 1.32$ & $26.63 \pm 1.32$ \\
\hline
\end{tabular}

Abbreviations: T, time; PM, physical Mixture; time in minutes. 
Table 5 In vitro Release Kinetics of CMN with Various Carriers (Mean $\pm S D, n=3$ )

\begin{tabular}{|l|l|l|l|l|l|l|}
\hline \multicolumn{7}{|l|}{ Correlation Coefficient $\left(\mathbf{r}^{2}\right)$} \\
\hline Carrier & Zero-order & First Order & Higuchi & Hixon Crowell & Korsmeyer- Peppas & Release Exponent (n) \\
\hline CMN-PXM-407 (I:5) & $0.49 I \pm 0.13$ & $0.724 \pm 0.36$ & $0.975 \pm 0.31$ & $0.988 \pm 0.12$ & $0.929 \pm 0.18$ & $0.07 I \pm 0.32$ \\
CMN-PXM-I88 (I:6) & $0.476 \pm 0.31$ & $0.536 \pm 0.17$ & $0.99 I \pm 0.26$ & $0.998 \pm 0.22$ & $0.956 \pm 0.26$ & $0.063 \pm 0.31$ \\
CMN-Gel-50/I3 (I:6) & $0.712 \pm 0.1 I$ & $0.812 \pm 0.22$ & $0.973 \pm 0.33$ & $0.993 \pm 0.18$ & $0.938 \pm 0.27$ & $0.22 I \pm 0.67$ \\
CMN-MNL (I:7) & $0.598 \pm 0.18$ & $0.628 \pm 0.16$ & $0.916 \pm 0.25$ & $0.963 \pm 0.14$ & $0.866 \pm 0.13$ & $0.134 \pm 0.36$ \\
\hline
\end{tabular}

Table 6 Similarity Factor Value $\left(f_{1}\right.$ and $\left.f_{2}\right)$ of Solid Dispersion

\begin{tabular}{|c|c|c|c|c|c|c|c|c|c|c|}
\hline \multicolumn{11}{|l|}{ D:C Ratio* } \\
\hline \multirow[t]{2}{*}{ Carrier } & \multicolumn{5}{|c|}{ Difference Factor $f_{\mathrm{I}}$} & \multicolumn{5}{|c|}{ Similarity Factor $f_{2}$} \\
\hline & $1: 3$ & $1: 4$ & $1: 5$ & $1: 6$ & $1: 7$ & $1: 3$ & $1: 4$ & $1: 5$ & $1: 6$ & $1: 7$ \\
\hline PXM-407 (I:5) & 11.08 & 2.79 & 13.90 & 10.61 & 10.92 & 54.81 & 76.47 & 48.70 & 55.10 & 55.08 \\
\hline Gel-50/I3 (I:6) & 44.35 & 47.13 & 41.64 & 37.97 & 34.27 & 24.75 & 21.36 & 25.00 & 27.49 & 30.14 \\
\hline MNL (I:7) & 66.90 & 68.97 & 64.37 & 61.54 & 57.80 & 15.92 & 13.13 & 15.70 & 17.12 & 19.08 \\
\hline
\end{tabular}

Abbreviation: *D:C, drug:carrier.

(436.48 and $388.28 \mathrm{M}^{-1}$ at 25 and $37^{\circ} \mathrm{C}$, respectively). The dissolution profiles of SD with PXM-407 (1:3 to 1:7) was thought similar ranges $\left(f_{2}>50\right)$, and difference factor $\left(f_{1}\right)$ ranges $\left(f_{1}<15\right)$, confirming the equivalence of two curves. The SD from the rest of the carriers, where not indicating values towards similar $\left(f_{2}, 11-26<50\right)$ and difference factor $\left(f_{1}, 40-75>15\right)$. This result was in good agreement with the previous results, suggesting mucoadhesive sustained delivery system and its anticipated mechanisms reported by Ige et al. ${ }^{47}$ From our results, we concluded that the CMN:PXM-407 would influence the dissolution abilities of the SD.

\section{Dyeing Effect}

Results of the dyeing test for pure CMN and its complex SDs with PXM-407, PXM-188, and Gel-50/13 are shown in Figure 3B. When $10 \mathrm{mg} \mathrm{CMN}$ was added to $15 \mathrm{~mL}$ of water, CMN floated due to its lipophilic nature and the solution was colorless. For the SDs with PXM-407, PXM-188, and Gel-50/13, the solution was deep yellow, yellow, and pale yellow, respectively, as shown in Figure 3B. Figure 3C shows that the cloth stained in the solution was colorless for pure CMN, characteristic yellow (PXM-407), yellow (PXM-188), and pale yellow color (Gel-50/13).

The interpretation of these dying effects was the solubilizing capacity that was greatest for the $\mathrm{CMN}-$ complex with PXM-407. This direct, novel dyeing test confirmed that the CMN-PXM-407 SD had a better coloring impact, Xu et al ${ }^{48}$ had reported similar descriptive and prevalence results, demonstrating that water solubility of drug could be increased significantly after incorporation in this complex.

\section{In silico Interaction}

The in silico interaction studies recognized and simplified the stability (better complex) of the drug and ligand molecules. A computer modeling of PXM and Gel-50/13 contributed selectivity to the points of interest of their molecular structure, as shown in Figure 3D. The ideal 1:1 ratio CMN/PXM complex encompass central hydrophobic polyoxypropylene (polypropylene oxide) chain for better hydrophobic interaction with the benzene rings of CMN and methyl group. Data has been presented in Figure 3D. Overall four hydrophobic interaction bonds formed in the distance range of 4.7-5.3 $\AA$. A tighter CMN/PXM cavity fit appears to explain the little changes in enthalpy $(\Delta \mathrm{H}=-11.9$ and $-7.50 \mathrm{~kJ} / \mathrm{mol})$ and positive changes in entropy $(\Delta \mathrm{S}=1$ and $2 \mathrm{~J} / \mathrm{mol} \mathrm{K})$. Detected as a complex formation, Gangurde et $\mathrm{al}^{49}$ suggested that these results are from enthalpy-entropy compensation.

An optimal 1:1 ratio complex configuration obtained for CMN with Gel-50/13 and interaction between the complex shows that the CMN hydroxyl group formed two conventional hydrogen bonds with the distance of $2.7 \AA$ and the ketone group of $\mathrm{CMN}$ formed two weak hydrogen bonds with the distance of $2.5 \AA$.

The optimal hydrogen interactions involved among the CMN/Gel-50/13 complex stand the complete interaction with the ketone group of CMN (Figure 3D) at the bond 
distance of $2.59 \AA$. Thus, confirming the high tendency of Gel-50/13 to form the molecular complex, obtained from PS study $\left(\mathrm{K}_{1: 1}=100,112\right.$ at 25 and $37^{\circ} \mathrm{C}$, respectively, Table 1). Subsequently, a complex appears to explain the significant changes in enthalpy $(\Delta \mathrm{H}=7.2 \mathrm{~kJ} / \mathrm{mol})$ and positive changes in entropy $(\Delta \mathrm{S}=6 \mathrm{~J} / \mathrm{mol} \mathrm{K})$ revealing a stable and soluble complex formed.

Overall, the in silico interaction study showed that the CMN with PXM was found to be better than Gel-50/13 complexes; molecular modeling data is in good argument with the results represented by PS study. This investigation provided a better emphasis on drug complex with the carrier, prior experimental work.

\section{Optimization of PXM-407 SD Variables}

The experimental results showed that the CMN-PXM-407

SD binary system prepared by the solvent evaporation method had enhanced solubility and dissolution of CMN, with better physicochemical properties. Subsequently, BBD was employed for the optimization of the PXM407 SD complex. The carrier (PXM-407) concentration $\left(\mathrm{X}_{1}\right)$, stirring rate $\left(\mathrm{X}_{2}\right)$, and temperature $\left(\mathrm{X}_{3}\right)$ were the independent variables for the three-factor, two-level design, and the dependent variables selected were aqueous solubility $\left(\mathrm{Y}_{1} ; \mathrm{Sol}_{\mathrm{aq}}, \mathrm{mg} \cdot \mathrm{mL}^{-1}\right)$ and release in 5 minutes $\left(\mathrm{Y}_{2} ; \mathrm{Rel}_{5 \text { min }}\right.$; Table 7).

The independent coded values of variables were as follows. Carrier concentration (CC): low value (-1) 500 $\mathrm{mg}$, high value $(+1) 700 \mathrm{mg}$; stirring rate (SR): low value (-1) $600 \mathrm{rpm}$, high value (+1) $800 \mathrm{rpm}$ (REMI-2MLH); and temperature (Temp): low value $(-1) 70$, high value $\left.(+1) 90^{\circ} \mathrm{C}\right)$. These were selected based on the outcomes from earlier experimentation: 17 experiments were performed with different conditions for the preparation of CMN- PXM-407 complex.

\section{Sol $_{\mathrm{aq}}(\mathrm{Mg} / \mathrm{mL})$}

The quadratic models were fitted for the dependent variables by the software. The polynomial model for a dependent variable $\mathrm{Y}_{1}$ is denoted by the following equation:

$$
\begin{aligned}
& \mathrm{Y}_{1}=+1.23+0.13 * \mathrm{X}_{1}+0.014 * \mathrm{X}_{2-0} .020 * \mathrm{X}_{3}-0.011 * \\
& \mathrm{X}_{1} * \mathrm{X}_{2-3} .570 \mathrm{E}-003 * \mathrm{X}_{1} * \mathrm{X}_{3-7} .250 \mathrm{E}-003 * \mathrm{X}_{2} * \mathrm{X}_{3-0} .049 \\
& * \mathrm{X}_{1}{ }^{2}-0.040 * \mathrm{X}_{2}{ }^{2}+0.025 * \mathrm{X}_{3}{ }^{2}
\end{aligned}
$$

The report for the analysis of variance (ANOVA) representing the quadratic predictive model was significant $(P=0.0001)$. The $\mathrm{R}^{2}$ value 0.9982 for $\mathrm{Y}_{1}\left(\mathrm{Sol}_{\mathrm{aq}} ; \mathrm{mg} \cdot \mathrm{mL}^{-1}\right)$ showed the similarity of the predicted (0.9778) and experimental responses and the values of CV (0.54) and $\operatorname{adj} . R^{2}(0.9959)$ indicated a high rate of precision and reliability of the investigated values and a high rate of correlation among the predicted and observed values, respectively. Su et $\mathrm{al}^{50}$ compared the result of predicted and observed values, in their descriptive study, demonstrating these values were well correlated and the other factors and their interactions were not significant $(P>0.05)$.

The interaction properties of the dynamic response were validated by graphical representation, which were dependent on the $\mathrm{CC}\left(\mathrm{X}_{1}\right)$, SR $\left(\mathrm{X}_{2}\right)$, and Temp $\left(\mathrm{X}_{3}\right)$, and the resulting aqueous solubility of $\mathrm{CMN}\left(\mathrm{Y}_{1}\right)$, as shown in Figure 4A. An increase in the concentration of PXM-407 from 500 to $700 \mathrm{mg}$, significantly enhanced the solubility of $\mathrm{CMN}$ from 0.99 to $1.3 \mathrm{mg} \cdot \mathrm{mL}^{-1}$. This revealed that the carrier was effectively responsible for the aqueous solubility of the drug. On the other hand, the aqueous solubility of CMN slightly decreased from 90 to $70^{\circ} \mathrm{C}$. The SR showed that a decrease in rpm (800 to 600) enhanced the aqueous solubility of $\mathrm{CMN}$, although this effect was not prominent, a similar result was obtained from the previous papers. $^{51}$

\section{$\operatorname{Rel}_{5 \min }(\%)$}

The following equation (Equation 9) represents the polynomial model for the response (release at $5 \mathrm{~min} ; \mathrm{Y}_{2}$ ):

$$
\begin{aligned}
& \mathrm{Y}_{2}=+81.42+1.08 * \mathrm{X}_{1}-0.47 * \mathrm{X}_{2}-0.21 * \mathrm{X}_{3}+0.19 * \\
& \mathrm{X}_{1} * \mathrm{X}_{2}-0.95 * \mathrm{X}_{1} * \mathrm{X}_{3}-0.13 * \mathrm{X}_{2} * \mathrm{X}_{3}-4.11 * \mathrm{X}_{1}{ }^{2}-2.97 \\
& * \mathrm{X}_{2}{ }^{2}-0.89 * \mathrm{X}_{3}{ }^{2}
\end{aligned}
$$

Of all the independent variables, $\mathrm{CC}$ was observed to have a significantly lower positive result on the release at 5 minutes, as was manifest in the narrow positive value for its coefficient. The negative values for the SR and Temp showed that the release decreased at a higher rate of stirring and temperature.

The negative effect of increasing the stirring rate was found to be greater than the effect of increasing the Temp. The interaction between the independent variables was also found to be significant. Overall, the model was typical $(P<0.0001$; F-value=102.46), while the lack of fit was not significant $(P=0.67 ; \mathrm{F}$-value $=0.6115)$. The predicted value $(0.9517)$ and adj. $\mathrm{R}^{2}(0.9828)$ values are important parameters, as reported by Chaudhary et al. ${ }^{52}$ The CC significantly affected the release of $\mathrm{CMN}$ from SD at the end of 5 minutes: if the $\mathrm{CC}$ was too small, release from SD could not be achieved at the desired level; when CC was $700 \mathrm{mg}$ the release was up to $75-80 \%$ (Figure $4 \mathrm{~B}$ ). Therefore, a 
Table 7 Effect of Independent Process Variables on Dependent Variable by Box-Behnken Design (C-SD)

\begin{tabular}{|c|c|c|c|c|c|c|c|}
\hline \multirow[t]{3}{*}{ Preparation Code } & \multicolumn{3}{|c|}{ Real Value (Coded Level) } & \multicolumn{2}{|c|}{ Sol $_{\mathrm{aq}}(\mathrm{mg} / \mathrm{mL})$} & \multicolumn{2}{|c|}{$\operatorname{Rel}_{5 \min }(\%)$} \\
\hline & & & & \multirow{2}{*}{$\begin{array}{l}\text { Actual } \\
Y_{\mathbf{I}}\end{array}$} & \multirow{2}{*}{$\begin{array}{l}\text { Predicted } \\
\mathbf{Y}_{\mathrm{I}}\end{array}$} & \multirow{2}{*}{$\begin{array}{l}\text { Actual } \\
Y_{2}\end{array}$} & \multirow{2}{*}{$\begin{array}{l}\text { Predicted } \\
\mathbf{Y}_{2}\end{array}$} \\
\hline & $\mathbf{X}_{\mathbf{I}}$ & $\mathbf{X}_{2}$ & $\mathbf{X}_{3}$ & & & & \\
\hline PI & $300(-1.00)$ & $600(-1.00)$ & $80(0.00)$ & 0.98 & 0.98 & 73.82 & 73.92 \\
\hline P2 & $700(1.00)$ & $600(-1.00)$ & $80(0.00)$ & 1.26 & 1.27 & 75.43 & 75.69 \\
\hline P3 & $300(-1.00)$ & $800(1.00)$ & $80(0.00)$ & 1.03 & 1.03 & 72.85 & 72.59 \\
\hline P4 & $700(1.00)$ & $800(1.00)$ & $80(0.00)$ & 1.27 & 1.27 & 75.24 & 75.14 \\
\hline P5 & $300(-1.00)$ & $700(0.00)$ & $70(-1.00)$ & 1.09 & 1.09 & 78.25 & 78.27 \\
\hline P6 & $700(1.00)$ & $700(0.00)$ & $70(-1.00)$ & 1.35 & 1.36 & 78.67 & 78.53 \\
\hline P7 & $300(-1.00)$ & $700(0.00)$ & $90(1.00)$ & 1.06 & 1.06 & 75.81 & 75.95 \\
\hline P8 & $700(1.00)$ & $700(0.00)$ & $90(1.00)$ & 1.30 & 1.31 & 80.03 & 80.01 \\
\hline P9 & $500(0.00)$ & $600(-1.00)$ & $70(-1.00)$ & 1.21 & 1.21 & 80.25 & 80.14 \\
\hline PIO & $500(0.00)$ & $800(1.00)$ & $70(-1.00)$ & 1.25 & 1.25 & 78.7I & 78.95 \\
\hline PII & $500(0.00)$ & $600(-1.00)$ & $90(1.00)$ & 1.19 & 1.19 & 79.71 & 79.47 \\
\hline $\mathrm{PI} 2$ & $500(0.00)$ & $800(1.00)$ & $90(1.00)$ & 1.19 & 1.20 & 78.68 & 78.79 \\
\hline $\mathrm{PI} 3$ & $500(0.00)$ & $700(0.00)$ & $80(0.00)$ & 1.23 & 1.23 & 81.52 & 81.42 \\
\hline $\mathrm{PI} 4$ & $500(0.00)$ & $700(0.00)$ & $80(0.00)$ & 1.22 & 1.23 & 81.04 & 81.42 \\
\hline PI5 & $500(0.00)$ & $700(0.00)$ & $80(0.00)$ & 1.23 & 1.23 & 81.02 & 81.42 \\
\hline PI6 & $500(0.00)$ & $700(0.00)$ & $80(0.00)$ & 1.23 & 1.23 & 81.50 & 81.42 \\
\hline PI7 & $500(0.00)$ & $700(0.00)$ & $80(0.00)$ & 1.22 & 1.23 & 82.00 & 81.42 \\
\hline
\end{tabular}

Notes: $X_{1}-$ carrier concentration $(\mathrm{mg})$; $\mathrm{X}_{2}$ - stirring speed $(\mathrm{rpm})$; and $\mathrm{X}_{3}-$ temperature $\left({ }^{\circ} \mathrm{C}\right)$ and $\mathrm{Y}_{1}-$ aqueous solubility $(\mathrm{mg} / \mathrm{mL})$; and $\mathrm{Y}_{2}-$ release at $5 \mathrm{minutes}(\%)$.

suitable CC was selected for the release of CMN from SD. These results indicated that the release rate of CMN increased rapidly by increasing the SR and decreasing the temperature; these effects were significant for $\mathrm{CC}$ of 500 and $700 \mathrm{mg}$, and the center point of SR and Temp revealed that the release of CMN significantly increased as the temperature decreased, which could be due to complete amorphization of CMN. The data obtained here are in good agreement with data from the previous literature. ${ }^{53}$

The optimized formulation (P18) validated for the response variables ( $\mathrm{Sol}_{\mathrm{aq}}$ and $\mathrm{Rel}_{5 \mathrm{~min}}$ ) was set at a maximum range, and the optimized preparation produced by the design noted as $500 \mathrm{mg}$ of PXM-407, $700 \mathrm{rpm} \mathrm{SR}$, and $70^{\circ} \mathrm{C}$ Temp. Accordingly, CMN- PXM-407 SD was prepared by the hot melt method with these specifications. The experimental values of $\mathrm{Sol}_{\mathrm{aq}}$ and $\mathrm{Rel}_{5 \mathrm{~min}}$ (1.266 $\mathrm{mg} \cdot \mathrm{mL}^{-1}$ and $81.76 \%$, respectively) were compared with the predicted values $(1.2736 \mathrm{mg} / \mathrm{mL}$ and $82.11 \%$ ) and the prediction error was found to be 0.46 and $0.63 \%$, respectively. The negligible errors confirmed that the established model was sound and the results of the predicted responses were in accordance with the investigational data. In conclusion, as a result of the BBD, a CMN-PXM-407 (1:5) complex with superior physicochemical properties was prepared. Subsequent experiments were carried out with this complex.

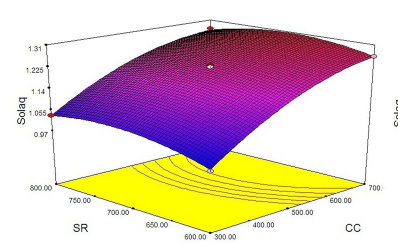

A
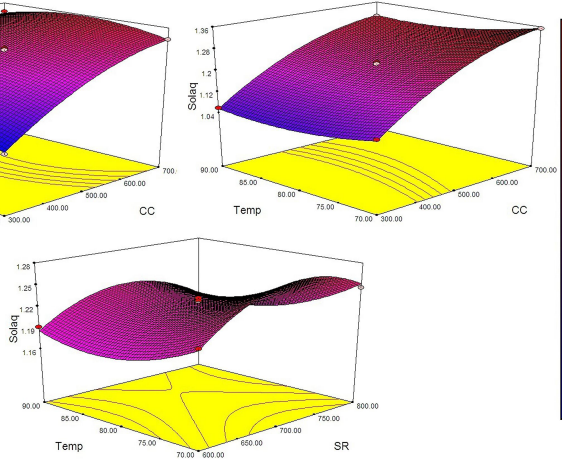
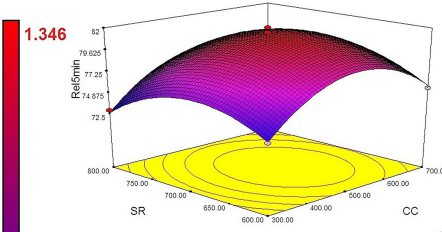

B

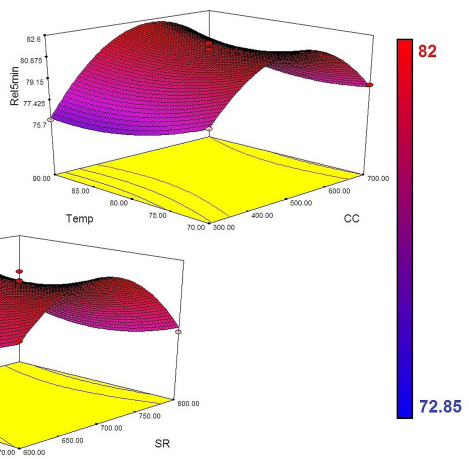

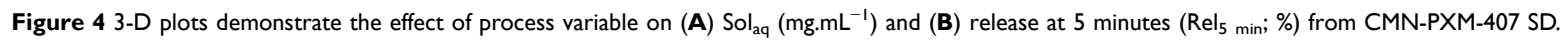




\section{DLS}

The hydrodynamic particle size of PM was $187.5 \mathrm{~nm}$ and the PDI was 0.299 (Figure 5A). This confirmed the bimodal size distribution, from which it was evident that the PM solution consisted of at least two constituents, this is in good agreement with results obtained from Mohamed et al. ${ }^{12}$ The hydrodynamic diameter of SD was $137.9 \mathrm{~nm}$, with a PDI of 0.069 (Figure 5A). The low PDI indicated the homogeneity of particle size distribution for the SD complex with CMN.

Zeta potential (ZP) is a significant parameter for understanding the state of the particle surface charge and stability (long-term storage) of the products; since the work by Pooja et $\mathrm{al}^{54}$ had reported similar descriptive and prevalence results, that the functionalized gold nanoparticles work as a biocompatible drug delivery carrier protecting drug from oxygen and hydrolysis. The ZP of the CMN-PM and CMN-SD complexes was found to be -8.20 and -26.1 , respectively, as shown in Figure 5A, which shows that the powdered $\mathrm{SD}$ was molecularly dispersed with $\mathrm{CMN}$ to give a superior complex than the PM.

\section{SEM}

Figure 5B shows the surface morphologies of i) pure $\mathrm{CMN}$, ii) PXM-407, iii) the PM, and iv) the SD. The pure CMN appeared as a characteristic prism-surfaced crystalline structure with average particle size of $15 \mu \mathrm{m}$, and the PXM-407 had a smooth surface with average particle size of $50 \mu \mathrm{m}$. The topological changes perceived in the SEM image of the PM complex seems to be the result of partial conversion of crystalline $\mathrm{CMN}$ to an amorphous structure. This change indicated the commencement of its partial complexation. Our result is in accordance with a similar study reported by Nayak and Pal. ${ }^{55}$

In contrast, in the SD image (as in Figure 5B) the drug surface appeared to be more porous, uniform, and homogeneously dispersed. The morphology of both the CMN and PXM-407 had disappeared at the molecular level, revealing their complete conversion into the molecular level amorphous form.

\section{The Cytotoxic Inhibition}

The cytotoxic outcomes of the MTT-reduction assay of pure CMN and optimized CMN-PXM-407 complex on

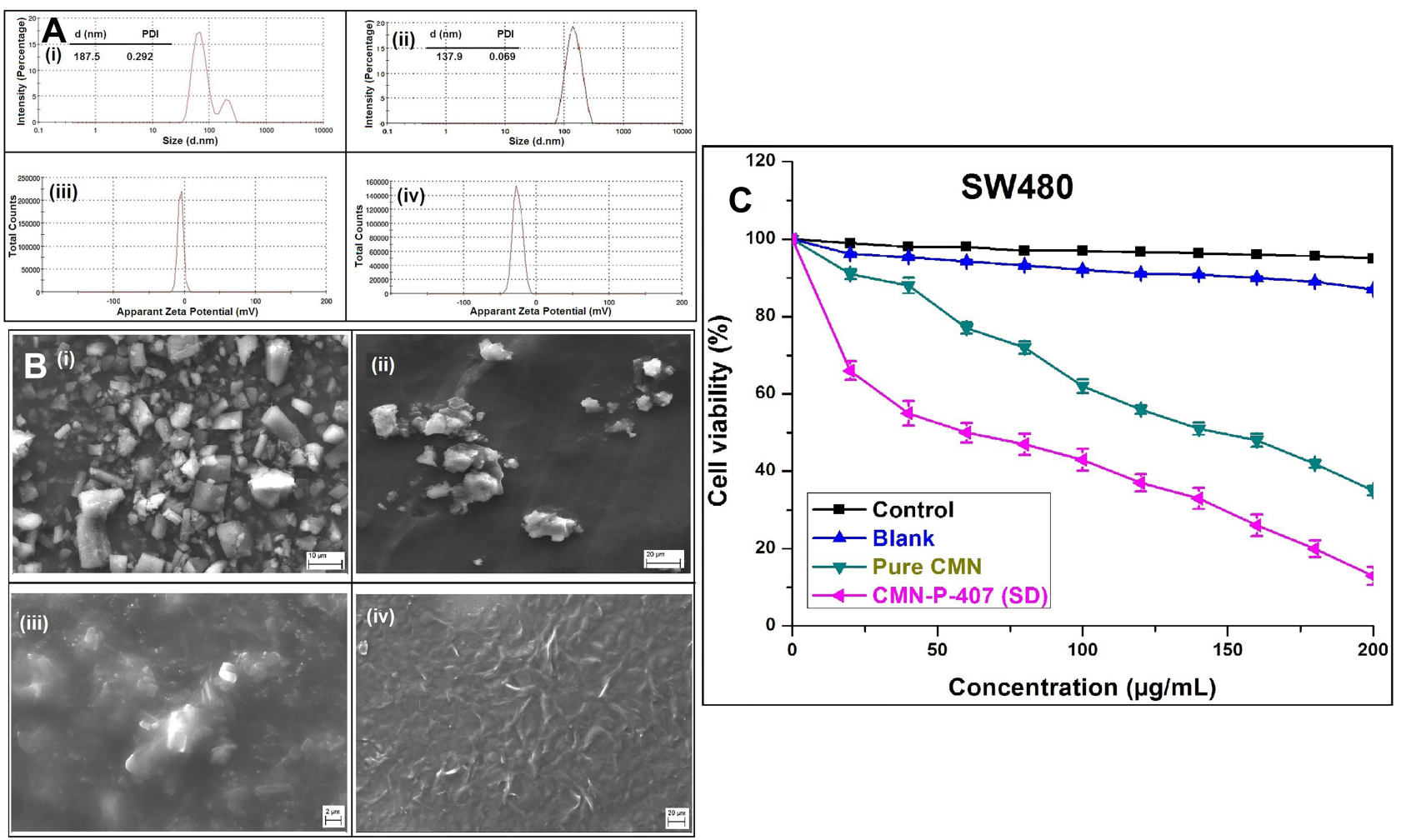

Figure 5 (A) Hydrodynamic PS (i and ii) and ZP (iii and iv) of PM (I:6) and SD (I:5) complex of CMN-PMX-407, (B) SEM image of (i) Pure CMN, (ii) PXM-407, (iii) PM (I:6), and (iv) SD (1:5) complex of CMN-PMX-407, and (C) in vitro cytotoxicity on SW480 cells line (Mean \pm SD, $n=3$ ). 
SW480 cells line are shown in Figure 5C. The $\mathrm{IC}_{50}$ values for the complexes were calculated as being around 52 $\mu \mathrm{M} \cdot \mathrm{mL}^{-1}$ for SW480, whereas for pure CMN it was 132 $\mu \mathrm{M} \cdot \mathrm{mL}^{-1}$. In contrast, this study revealed that there was no cytotoxic contribution on adenocarcinoma cells while treated with control and blank (pure PMX-407). The final outcomes of the MTT assay showed that the soluble complex exhibited better cytotoxicity than pure CMN. This could be due to variations in cellular uptake leading to the improved effect of the complex. Sun et al ${ }^{56}$ compared the result of the pure CMN and solubilized solution, the latter one exhibited prolonged inhibitory activity in cancer cells, as well as time-dependent increases in intracellular uptake. The effects of this assay indicated that the SD complex could transport the drug to SW480 cells using endocytic process by active targeting combined with better cytotoxicity and aqueous solubility of CMN. The cell viability gradually declined with increasing concentration of CMN-PMX (SD) and pure CMN, while SD (soluble CMN) showed a significantly better cytotoxic effect than pure CMN.

\section{Cell Death}

\section{AO/EB Staining}

The cytotoxic effect produced by the complex on SW480 cells was shown as cell viability or control cells. Unbroken chromatin with an undamaged cell membrane appeared as a bright green color, indicating that the cells did not experience apoptotic changes. The complex SD treatment produced highly effective apoptosis, increasing both necrosis and non-viable cells, compared to treatment with pure CMN. Types of morphological changes such as cytological and geologies of the chromatin changes during apoptosis were measured and the cells were classified as follows. 1) Viable cells: the cells had a well-organized structure and uniform chromatin with a green fluorescing nucleus (Figure 6A). 2) Early apoptotic cells: fragmentation of DNA had just begun, there was intact cell structure and a build-up of chromatin with green fluorescing nuclei (Figure 6A). 3) Late apoptotic cells: DNA and chromatins were cleaved/ condensed or damaged with orange to red fluorescing nuclei (Figure 6A). 4) Necrotic cells: The cell membrane was a swollen or substantial structure, DNA and chromatin fragmentations were absent, with an orange to red fluorescing nucleus (Figure 6A). The outcomes of this study suggested that the SD complex treatment caused cell death mainly through apoptosis and a small amount through necrosis (Figure 6C); this was true for both SW480, and was more pronounced than with pure $\mathrm{CMN}$ treatment. In addition, Abel and Sarah ${ }^{57}$ strongly recommended the dual AO/EB staining was able to identify even mild DNA damage to differentiate normal, early apoptotic, late apoptotic, necrotic, dead cells, and nuclear morphology.

\section{Hoechst Staining}

Cytological changes of the SW480 cells were detected after treatment with the $\mathrm{IC}_{50}$ concentrations of the complexes for 24 hours. A manual count of normal and abnormal cells was performed using Hoechst 33,258 staining of the Sw480 cells, shown in Figure 6B. This method showed abnormalities in the cell cytology, with specific reference

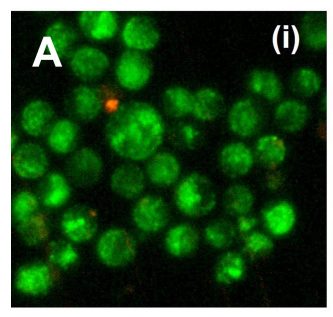

Control

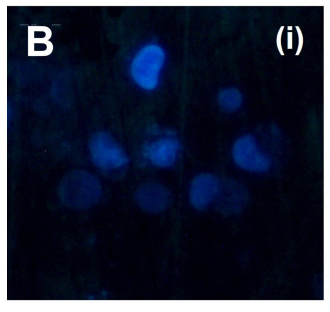

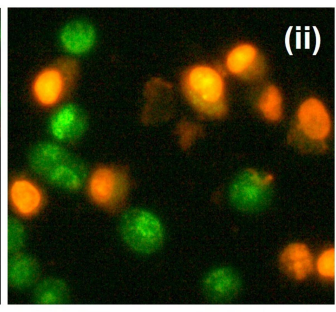

Pure CMN

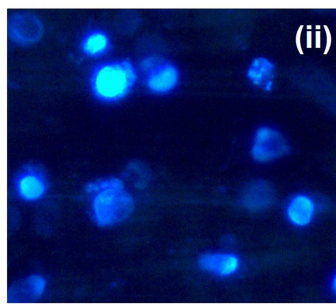

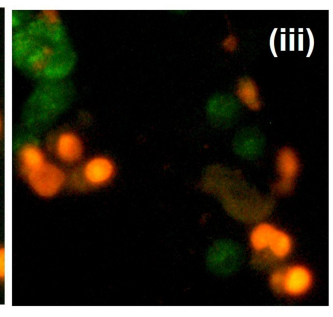

CMN-PMX-407 (SD)

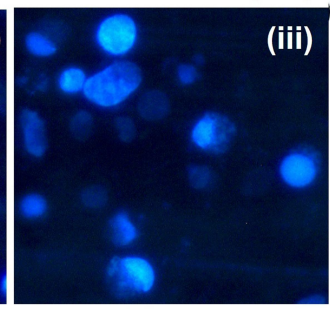

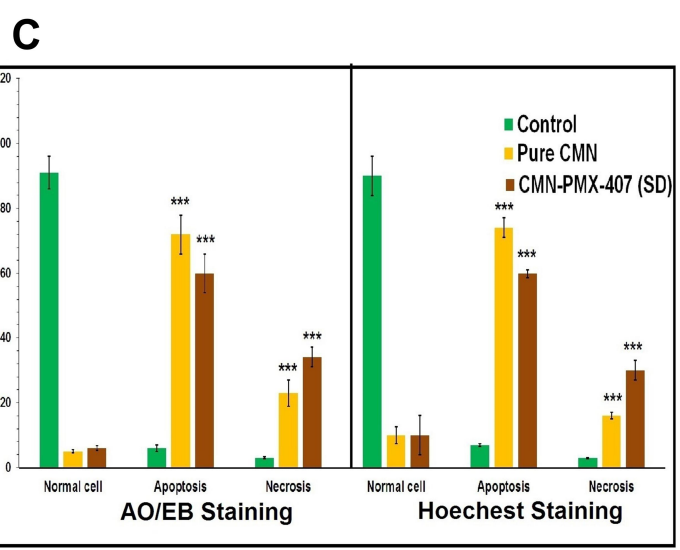

Figure 6 Apoptotic morphology of (A) AO/EB and (B) Hoechst staining pictured using fluorescent microscope on SW480 cells; (i) control; (ii) pure CMN; and (iii) CMNPXM-407 SD complex, and (C) percentage of normal, apoptotic, and necrotic cells at 24 hours treatment (***P<0.00I calculated by the one-way ANOVA test). 
to the nucleus core and cytoplasm at the primary level to identify apoptosis (Figure 6B; ii and iii). Dhivya et al ${ }^{58}$ obtained asimilar result of apoptosis-inducing properties of a mononuclear copper (II) complex on both late and early apoptotic cells appeared as cell shrinkage with an intact membrane structure, chromatin build-up with discontinuity of DNA. A small number of necrotic cells were also observed (Figure 6B). The percentage of viable, nonviable, apoptotic, and necrotic cells were estimated as shown in Figure 6C.

\section{DNA Fragmentation}

DNA fragmentation assay showed a "fragment or ladder" pattern of DNA and :100 bp intervals (Lane 1). Lanes were loaded with equimolar concentrations of DNA extracted from the cells of control, pure CMN-treated, and SD complex-treated SW480 cells, as shown in Figure 7A. Lane 2 (control) showed a DNA band with an unbroken pattern. CMN-treated (lanes 3) and SD complex (Lane 4) had a smeared pattern owing to DNA fragmentation occurring. Larger fragment or laddering of DNA was observed in the lane treated with SD complex due to greater DNA fragmentation occurring; this indicated that apoptosis occurred by the action of nuclear enzyme oligonucleosomes, which was reported by Vignesh et al. ${ }^{59}$ An in-depth visualization displayed the outstanding outcome on the initiation of apoptosis as evidenced by the presence of DNA ladders in the samples treated with complex, exhibiting more active cell death compared to pure CMN (more cleavage of the DNA “ladder").

\section{Cell Cycle Analysis}

Propidium iodide staining was used to enable morphological investigation. After 24 hours of treatment, the SW480 cells were analyzed by flow cytometry for the phase of cell cycle arrest and initiation of apoptosis. The data has been shown in Figure 7B. The SW480 cells at G2/M phase, only $14.76 \%$ of the cell population was observed for control (Figure 7B), whereas it was $31.49 \%$ and $43.26 \%$, respectively, for pure $\mathrm{CMN}$ and the SD complex. While increasing the cell population at $\mathrm{G} 2 / \mathrm{M}$ phase, the cell population at $\mathrm{G} 1(0.59,0.53$, $0.48 \%$ ) and $\mathrm{S}(8.97,8.04,7.61 \%)$ phases subsequently decreased after treatment with pure $\mathrm{CMN}$ and $\mathrm{SD}$ complex. The soluble CMN complex (CMN-PMX-407) prepared as $\mathrm{SD}$ effectively blocked the colorectal adenocarcinoma cells at the G2/M phase: the cytotoxicity of CMN killed the cancer cells by triggering cell death via numerous caspase-mediated paths, which activated the apoptotic pathway subsequently treated with SD complex. This result was in good agreement with the previous results, suggesting the improved uptake and retention with C-SLN by anticipated mechanisms. ${ }^{60}$

\section{Western Blotting}

The soluble curcumin of SD reduced the expression of Cyclin D1 protein more significantly than pure CMN, as

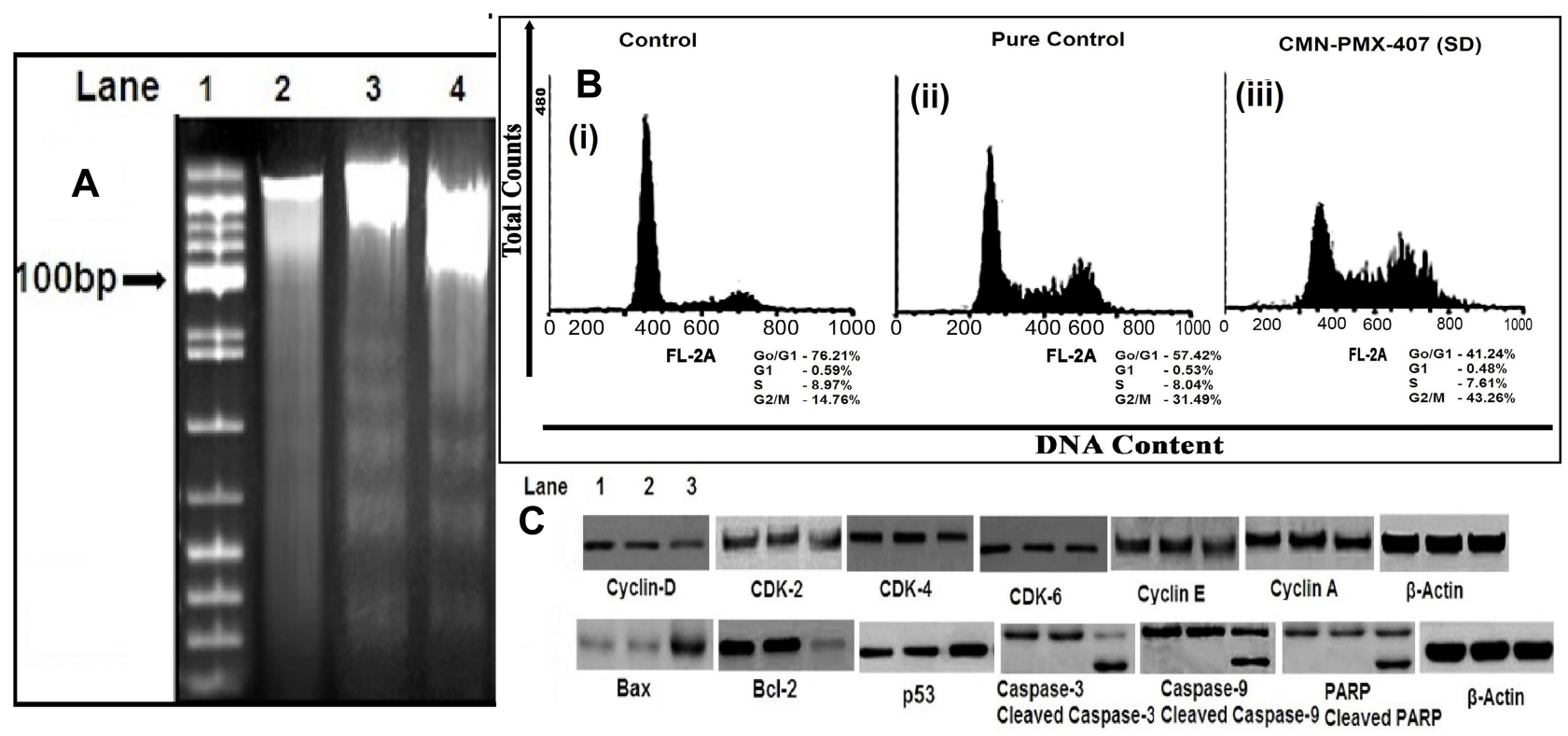

Figure 7 Gel electrophoresis (A) of DNA of treated SW480 cells; Lane I: 100 bp ladder, Lane 2:Control, Lane 3: Pure CMN, Lane 4: CMN-PMX-407 (SD), (B) The cell cycle analysis effects on SW480 cells (i) control, (ii) pure CMN, and (iii) CMN-PMX-407 (SD); the non-small colon cancer cells were cultured for 24 h, and (C) Western blot representing the various protein expression during apoptosis; Lane I: control, Lane 2: pure CMN, Lane 3: CMN-PMX-407 (SD). 
shown in Figure 7C. Cyclin E band was shown to be a stronger band at CMN-PMX-407 SD lane than free CMN. The downregulation proteins such as cdk-2, cdk-4, and cdk-6 induced retinoblastoma $(\mathrm{Rb})$ phosphorylation observed with apoptosis in SW480 cells. A previous study had shown that apoptosis could increase the expression of Bax, thus leading to an increased ratio of Bax to Bcl2 on SW480 cells with stronger death stimulations. ${ }^{61}$

The CMN-SD induced cell proliferation reduced the antagonistic effect produced by cdk- 6 protein and significantly reduced the expression of $\mathrm{Cdk}-2$ and $\mathrm{Cdk}-4$. Remarkably, the outcome of cell death is maximum based on the quantity of Bcl-2 and Bax rather the volume of Bcl-2 alone. The Bax (tumor-suppressing protein) and Bcl-2 (tumor-triggering proteins) were stimulated by SW480 cells by treating with CMN-SD, as shown in Figure 7C. The p53 directs the stretch signs of apoptosis and cell cycle capture [63]. Soluble CMN was shown to upregulate the levels of tumor suppressing protein p53 and caspases, a collection of cysteine acid proteases which are considered as critical factors in apoptosis. The outcome of treated cells of CMN-SD triggered fragmentation on caspase-3 and caspase-9. Also, the fragmented type of PARP stimulates cell cutting or fragment and functioned as an indicator of cells undergoing apoptosis. The Western blot analysis confirmed that CMN-SD significantly elevates the levels of caspase 3, caspase 9, and PARP proteins. Recently, Jiang et $\mathrm{al}^{62}$ reviewed the deficiency of work by Kim et al, ${ }^{61}$ but a considerable source of information had been shown that triggering the caspase protein family activates the apoptotic development in cells. Activation of caspase- 3 caused in the apoptosis of cell, with cell shrinkage, membrane blabbing, and internucleosomal DNA fragmentation.

\section{Conclusion}

From the findings of this study, it can be concluded that the ideal stoichiometric ratio of CMN to carrier was $1: 1$ to enhance the aqueous solubility of CMN. The formulated molecular complex of CMN-PXM-407 was found to be effective against colorectal cancer (CRC) as compared to pure CMN against SW480 cells. Flow cytometry analysis confirmed the mechanism of cell cycle arrest and it was at G2/M phase. In addition, DNA fragmentation analysis showed the complex induced significant DNA damage during apoptosis. The profound efficiency of optimized CMN-PMX-407 complex assured its suitability for the treatment of CRC, providing a novel scheme for improving the application of existing cancer treatment.

\section{Acknowledgments}

The authors are thankful to the King Institute of Preventive Medicine and Research, Chennai, India, for given facilities to carry out flow cytometry, DNA fragmentation, and Western blot analysis, etc. Also they are thankful to the National Centre for Alternatives to Animal Experiments (NCAAE), Bharathidasan University, India, for providing facilities to perform cell line studies.

\section{Disclosure}

The authors report no conflicts of interest for this work.

\section{References}

1. Nurgali K, Jagoe RT, Abalo R. Editorial: adverse Effects of Cancer Chemotherapy: anything New to Improve Tolerance and Reduce Sequelae? Front Pharmacol. 2018;9:245. doi:10.3389/fphar.2018.00245

2. Akram M, Shahab-Uddin AA, Usmanghani K, Hannan A, Mohiuddin E, Asif M. Curcuma longa and curcumin: a review article. Rom J Biol -Plant Biol. 2010;55:65-70.

3. Sachin SK, Kailash CS, Gyana R. High Performance Thin Layer Chromatography Fingerprint Profile of Rhizome Extracts of Five Important Curcuma Species. Proc Natl Acad Sci India Sect B Biol Sci. 2016;87:4. doi:10.1007/s40011-016-0709-z

4. Park J. Anti-carcinogenic properties of curcumin on colorectal cancer. World J Gastrointest Oncol. 2010;2(4):169-176. doi:10.4251/ wjgo.v2.i4.169

5. Ruby AJ, Kuttan G, Babu KD, Rajasekharan KN, Kuttan R. Antitumour and antioxidant activity of natural curcuminoids. Cancer Letters. 1995;94(1):79-83. doi:10.1016/0304-3835(95)03827-J

6. Kanai M, Imaizumi A, Otsuka Y, et al. Dose-escalation and pharmacokinetic study of nanoparticle curcumin, a potential anticancer agent with improved bioavailability, in healthy human volunteers. Cancer Chemother Pharmacol. 2012;69(1):65-70. doi:10.1007/s00280-011-1673-1

7. Garcea G, Berry DP, Jones DJ, et al. Consumption of the putative chemopreventive agent curcumin by cancer patients: assessment of curcumin levels in the colorectum and their pharmacodynamics consequences. Cancer Epidemiol Biomarkers Prev. 2005;14:120-125.

8. Savjani KT, Gajjar AK, Savjani JK Drug Solubility: importance and Enhancement Techniques. International Scholarly Research Notices/ 2012: Article ID 195727

9. Descamps M, Willart JF. Perspectives on the amorphisation/milling relationship in pharmaceutical materials. Adv Drug Deliv Rev. 2016;100:51-66. doi:10.1016/j.addr.2016.01.011

10. Kamalakkannan V, Puratchikody A, Masilamani K, Senthilnathan B. Solubility enhancement of poorly soluble drugs by solid dispersion technique-A review. J Pharm Res. 2010;3:2314-2321.

11. Higuchi T, Connors KA. Phase-solubility techniques. Adv Anal Chem and Instrumen. 1965;4:117-212.

12. Mohamed JMK, Kavitha K, Karthikeyini SC, Nanthineeswari S. Soluble curcumin prepared using four different carriers by solid dispersions: phase solubility, molecular modelling and physicochemical characterization. Trop J Pharm Res. 2019;18(8):1581-1588.

13. Vasoya JM, Desai HH, Gumaste SG, et al. Development of Solid Dispersion by Hot Melt Extrusion Using Mixtures of Polyoxylglycerides With Polymers as Carriers for Increasing Dissolution Rate of a Poorly Soluble Drug Model. J Pharm Sci. 2019;108(2):888-896. doi:10.1016/j.xphs.2018.09.019 
14. Palanisamy M, Khanam J. Solid dispersion of prednisolone: solid state characterization and improvement of dissolution profile. Drug Dev Ind Pharm. 2011;37(4):373-386. doi:10.3109/03639045.2010.513984

15. Dhanalekshmi UM, Poovi G, Kishore N, Reddy PN. Reddy PN In vitro characterization and in vivo toxicity study of repaglinide loaded poly (methyl methacrylate) nanoparticles. Int J Pharm. 2010;396(12):194-203. doi:10.1016/j.ijpharm.2010.06.023

16. Diaz DA, Colgan ST, Langer CS, Bandi NT, Likar MD, Van Alstine L. Alstine LV Dissolution Similarity Requirements: how Similar or Dissimilar Are the Global Regulatory Expectations? The AAPS Journal. 2016;18(1):15-22. doi:10.1208/s12248-015-9830-9

17. Liu L, Xu J, Zheng $\mathrm{H}$, et al. Inclusion complexes of laccaic acid A with $\beta$-cyclodextrin or its derivatives: phase solubility, solubilization, inclusion mode, and characterization. Dyes and Pigments. 2017;139:737-746. doi:10.1016/j.dyepig.2017.01.001

18. Camelia N, Corina A, Angela N, Crina-Maria M. Phase solubility studies of the inclusion complexes of repaglinide with $B$-cyclodextrin and $\beta$-cyclodextrin derivatives. FARMACIA. 2010;58:620628.

19. Chaudhary H, Kohli K, Amin S, Rathee P, Kumar V. Optimization and formulation design of gels of diclofenac and curcumin for transdermal drug delivery by Box-Behnken statistical design. J Pharm Sci. 2011;100(2):580-593. doi:10.1002/jps.22292

20. Kumar NS, Ganapathy M, Sharmila S, Shankar M, Vimalan M, Potheher IV. $\mathrm{ZnO} / \mathrm{Ni}(\mathrm{OH})_{2}$ core-shell nanoparticles: synthesis, optical, electrical and photoacoustic property analysis. J Alloys Compd. 2017;703:624-632. doi:10.1016/j.jallcom.2017.01.323

21. Dhananjay D, Gurpreet K, Anandan R, Loganathan G, Trinuclear Zinc-Schiff A. Base Complex: biocatalytic Activity and Cytotoxicity. Eur J Inorg Chem. 2014;1-10. doi:10.1002/ejic.201402158

22. Ramachandran M, Anandan S, Ashokkumar M. A luminescent onoff probe based calix[4] arene linked through triazole with ruthenium (ii) polypyridine complexes to sense copper(ii) and sulfide ions. New J Chem. 2019;43(25):9832-9842. doi:10.1039/C9NJ01632E

23. Nagaraj K, Subramanian A, Sankaralingam A. Synthesis, CMC determination, and intercalative binding interaction with nucleic acid of a surfactant-copper (II) complex with modified phenanthroline ligand (dpq). J Biomol Struct Dyn. 2014. doi:10.1080/07391102.2013. 879837

24. Dasiram JD, Ganesan R, Kannan J, Kotteeswaran V, Sivalingam N. Curcumin inhibits growth potential by G1 cell cycle arrest and induces apoptosis in p53-mutated COLO 320DM human colon adenocarcinoma cells. Biomed Pharmacother. 2017;86:373-380.

25. Mosieniak G, Adamowicz M, Alster O, et al. Curcumin induces permanent growth arrest of human colon cancer cells: link between senescence and autophagy. Mech Ageing Dev. 2012;133:444-455.

26. Tu LC, Chou CK, Chen CY, Chang YT, Shen YC, Yeh SF. Characterization of the cytotoxic mechanism of Mana-Hox, an analog of manzamine alkaloids. Biochim Biophys Acta. 2004;1672:148156.

27. Moideen MMJ, Karuppaiyan K, Kandhasamy R, Seetharaman S. Skimmed milk powder and pectin decorated solid lipid nanoparticle containing soluble curcumin used for the treatment of colorectal cancer. J Food Process Eng. 2019;43(3):1-15.

28. Le HT, Jeon HM, Lim CW, Kim TW. Synthesis, Cytotoxicity, and phase-Solubility Study of Cyclodextrin Click Clusters. J Pharm Sci. 2014;103:3183-3189.

29. Bandari S, Jadav S, Eedara BB, Dhurke R, Jukanti R. Enhancement of Solubility and Dissolution Rate of Loratadine with Gelucire 50/13. J Pharm Innov. 2014;9:141-149.

30. Iacovino R, Rapuano F, Caso JV, et al. $\beta$-Cyclodextrin Inclusion Complex to Improve Physicochemical Properties of Pipemidic Acid: characterization and Bioactivity Evaluation. Int J Mol Sci. 2013;14(7):13022-13041.

31. Bodratti AM, Alexandridis P. Formulation of Poloxamers for Drug Delivery. J Funct Biomater. 2018;9:11.
32. Cesareo J, Santosa JL, Perez-Martíneza J, Gomez-Pantoja ME, Moyanoab JR. Enhancement of albendazole dissolution properties using solid dispersions with Gelucire 50/13 and PEG 15000. J Drug Deliv Sci Tec. 2017;42:261-272.

33. Uzqueda M, Martın C, Zornoza A, Sanchez M, Oharriz MCM, Velaz I. Characterization of complexes between Naftifine and cyclodextrins in solution and in the slid state. Pharm Res. 2006;23:980-988.

34. Ban E, Park M, Jeong S, et al. Poloxamer-Based Thermoreversible Gel for Topical Delivery of Emodin: influence of P407 and P188 on Solubility of Emodin and Its Application in Cellular Activity Screening. Molecules. 2017;22:1-10.

35. Mohanraj P, Jasmina K. Effect of physiochemical variables on phase solubility and dissolution behavior of indomethacin solid dispersion system. J Pharm Invest. 2013;44:147-162.

36. Kurniawansyah F, Quachie L, Mammucari LR, Foster NR. Improving the dissolution properties of curcumin using dense gas antisolvent technology. Int J Pharm. 2017;521:239-248.

37. Zajc N, Obreza A, Bele M, Srci S. 'Physical properties and dissolution behavior of nifedipine/mannitol solid dispersions prepared by hot melt method'. Int J Pharm. 2005;291:pp. 51-58.

38. Jang OJ, Kim ST, Lee K, Oh E. Improved bioavailability and antiasthmatic efficacy of poorly soluble curcumin solid dispersion granules obtained using fluid bed granulation. Bio-Med Mat Eng. 2014;24:413-429.

39. Avinash BG, Harish SK, Sharadchandra DJ, Diwakar RJ, Mariam SD, Purnima DA. Enhanced solubility and dissolution of curcumin by a hydrophilic polymer solid dispersion and its insilico molecular modeling studies. J Drug Deliv Sci Tec. 2015;29:226-237.

40. Fini A, Moyano JR, Gine JM, Perez-Martinez JI, Rabasco AM. 'Diclofenac salts, II. Solid dispersions in PEG6000 and Gelucire 50/13'. Eur J Pharm Biopharm. 2005;60:99-111.

41. Chen Z, Xia Y, Liao S, et al. Thermal degradation kinetics study of curcumin with nonlinear methods. Food Chem. 2014;155:81-86.

42. Masek A, Chrzescijanska E, Zaborski M. Characteristics of curcumin using cyclic voltammetry, UV-vis, fluorescence and thermogravimetric analysis. Electrochim Acta. 2013;107:441-447.

43. Popat A, Karmakar S, Jambhrunkar S, Xu C, Yu C. Curcumincyclodextrin encapsulated chitosan nanoconjugates with enhanced solubility and cell cytotoxicity. Coll Surf B. 2014;117:520-527.

44. Sadeghi F, Ashofteh M, Homayouni A, Abbaspour M, Nokhodchi A, Garekani HA. Antisolvent precipitation technique: A very promising approach to crystallize curcumin in presence of polyvinyl pyrrolidon for solubility and dissolution enhancement. Coll Surf B Biointer. 2016;147:258-264.

45. Li J, Lee IW, Shin GH, Chen X, Park HJ. Curcumin-Eudragit ${ }^{\circledR}$ E PO solid dispersion: A simple and potent method to solve the problems of curcumin. Eur J Pharm Biopharm. 2015;94:322-332.

46. Dhruba JS, Anupama S, Prithusayak M, Anil K, Parmar BS. Synthesis and Characterization of Poly (CMC-g-cl-PAam/Zeolite) SuperabsorbenComposites for Controlled Delivery of Zinc Micronutrient: swelling and Release Behavior. Polym Plast Technol Eng. 2015;54(4):357-367.

47. Ige PP, Kawade R, Belgamwar V, et al. Development of pellets of nifedipine using HPMC K15 M and j-carrageenan as mucoadhesive sustained delivery system and in vitro evaluation. Iran Polym J. 2013;22:911-921.

48. Xu S, Chen J, Wang B, Yang Y. Sustainable and hydrolysis-free dyeing process for polylactic acid using nonaqueous medium. ACS Sustain Chem Eng. 2015;1.3:1039-1046.

49. Gangurde AB, Kundaikar HS, Javeer SD, Jaiswar DR, Degani MS, Amin PD. Enhanced solubility and dissolution of curcumin by a hydrophilic polymer solid dispersion and its In-silico molecular modeling studies. J Drug Deliv Sci Tec. 2015;29:226-237.

50. Su SN, Nie HL, Zhu LM, Chen TX. Optimization of adsorption conditions of papain on dye affinity membrane using response surface methodology. Bioresour Technol. 2009;100:2336-2340. 
51. Baig MS, Ahad A, Aslam M, Imam SS, Ali MAA. Application of Box- Behnken design for preparation of levofloxacin-loaded stearic acid solid lipid nanoparticles for ocular delivery: optimization, in vitro release, ocular tolerance, and antibacterial activity. Int J Biol Macromol. 2016;85:265-270.

52. Chaudhary H, Rohilla A, Rathee P, Kumar V. Optimization and formulation design of carbopol loaded Piroxicam gel using novel penetration enhancers. Int J Biol Macromol. 2013;55:246-253.

53. Zhao B, Zhang J, Guo XX, Wang J. Microwave-assisted extraction, chemical characterization of polysaccharides from Liliumdavidii var. unicolor Salisb and its Antioxidant activities evaluation. Food Hydrocoll. 2013;31:346-356.

54. Pooja D, Panyaram S, Kulhari H, Reddy B, Rachamalla SS, Sistla R. Natural polysaccharide functionalized gold nanoparticles as biocompatible drug delivery carrier. Int J Biol Macromol. 2015;80:48-56.

55. Nayak AK, Pal D. Formulation, optimization and evaluation of jackfruit seed starch alginate mucoadhesive beads of metformin $\mathrm{HCl}$. Int J Biol Macromol. 2013;59:264-272.

56. Sun J, Bi C, Chan HM, Sun S, Zhang O, Zheng Y. Curcumin-loaded solid lipid nanoparticles have prolonged in vitro antitumour activity, cellular uptake and improved in vivo bioavailability. Coll Surf B Biointer. 2013;111:367-375.
57. Abel DAS, Sarah KB. Honey is cytotoxic towards prostate cancer cells but interacts with the MTT reagent: considerations for the choice of cell viability assay. Food Chem. 2018;241:70-78.

58. Dhivya R, Palaniandavar M, Jaividhya P, Mathan G, Akbarsha MA, Riyasdeen A. In vitro antiproliferative and apoptosis-inducing properties of a mononuclear copper (II) complex with dppz ligand, in two genotypically different breast cancer cell lines. Biometals. 2015;28:929-943.

59. Vignesh G, Senthilkumar R, Paul P, Periasamy VS, Akbarsha MA, Arunachalam S. Protein binding and biological evaluation of a polymer-anchored cobalt (III) complex containing a 2,2/ bipyridine ligand. RSC Adv. 2014;4:57483-57492.

60. Oberhammer F, Wilson JW, Dive C, et al. Apoptotic death in epithelial cells: cleavage of DNA to 300 and/or $50 \mathrm{~kb}$ fragments prior to or in the absence of internucleosomal fragmentation. THE EMBO J. 1993;12:3679-3684.

61. Kim KT, Zaikova T, Hutchison JE, Tanguay RL. Gold nanoparticles disrupt zebra fish eye development and pigmentation. Toxicol Sci. 2013;133:275-288.

62. Jiang S, Zhu R, He X, et al. Enhanced photocytotoxicity of curcumin delivered by solid lipid nanoparticles. Int J Nanomed. 2017;12:167178 .

\section{Publish your work in this journal}

Drug Design, Development and Therapy is an international, peerreviewed open-access journal that spans the spectrum of drug design and development through to clinical applications. Clinical outcomes, patient safety, and programs for the development and effective, safe, and sustained use of medicines are a feature of the journal, which has also been accepted for indexing on PubMed Central. The manuscript management system is completely online and includes a very quick and fair peer-review system, which is all easy to use. Visit http://www. dovepress.com/testimonials.php to read real quotes from published authors. 